\title{
The Effects of Climate Change on the Phenological Interactions of Plants and Pollinators
}

\section{David W. Inouye \\ University of Maryland \\ Rocky Mtn. Biological Lab}

Presented at the 2009 Ecological Society of America meeting Albuquerque, NM

\section{Symposium 14}

Phenology, the Interdisciplinary Canary: Linkages Between Ecology andn Sustainable Decisior Making in a Dynamic Environment 


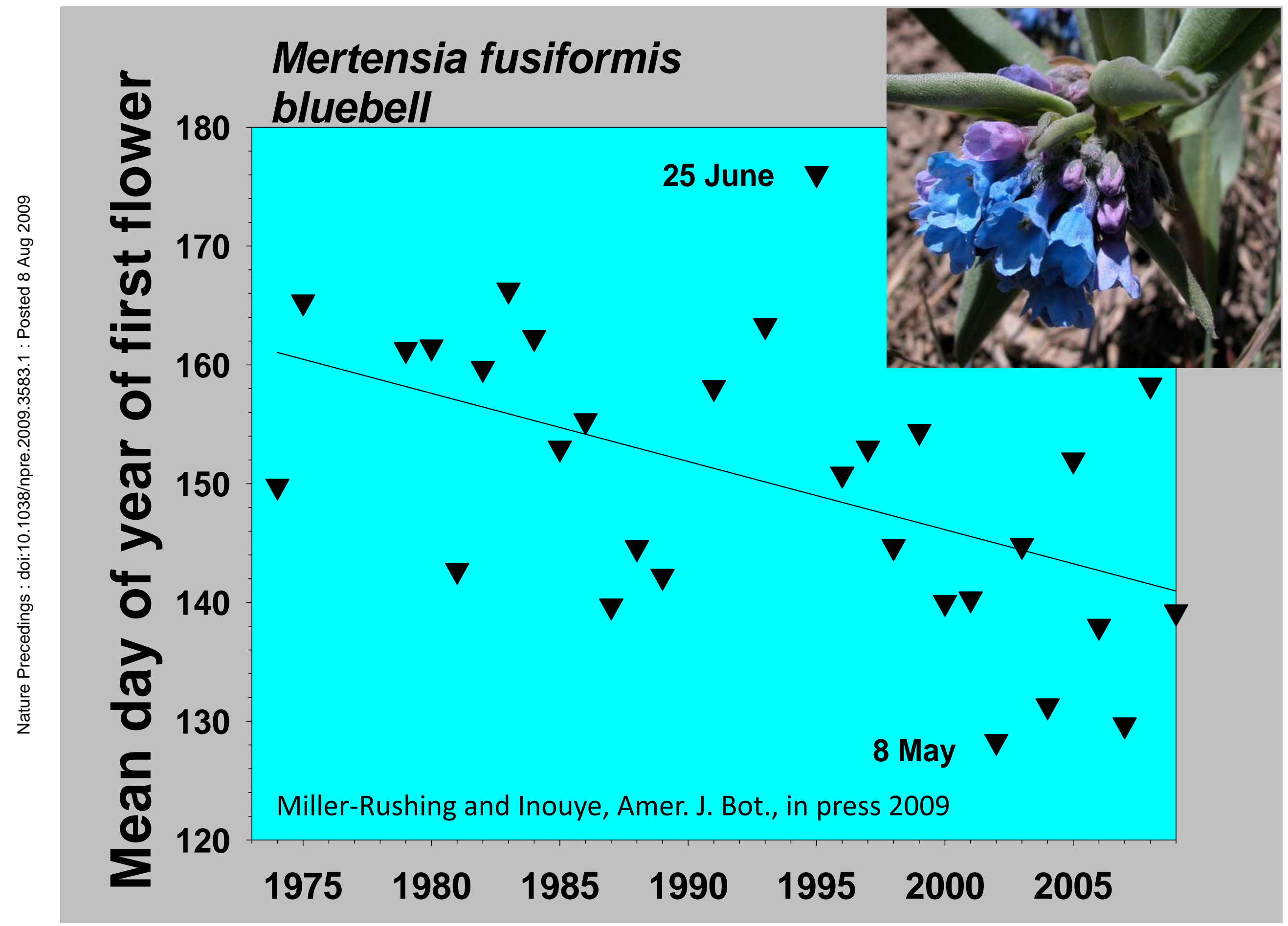




\section{Possible Effects on Interactions}

- Plants and pollinators use the same environmental cues for phenology

- Phenology remains synchronized

- They use the same cues, but respond at different rates to changes in the cues

- Uncoupling of historical phenological relationships

- Rare and common species respond differently

- Uncoupling of historical phenological relationships 


\section{More Possible Effects}

- Phenology and abundance are linked

- Increases variability of demographic parameters

- Differential changes across gradients

- Pollinators move up mountains faster than plants

- Pollinators change latitude faster than plants 


\section{Consequences}

- Trophic mismatches

- Changes in interaction webs

- Range changes

- Local extinctions

- Global extinctions

- Evolution

- New interactions 


\section{it on}

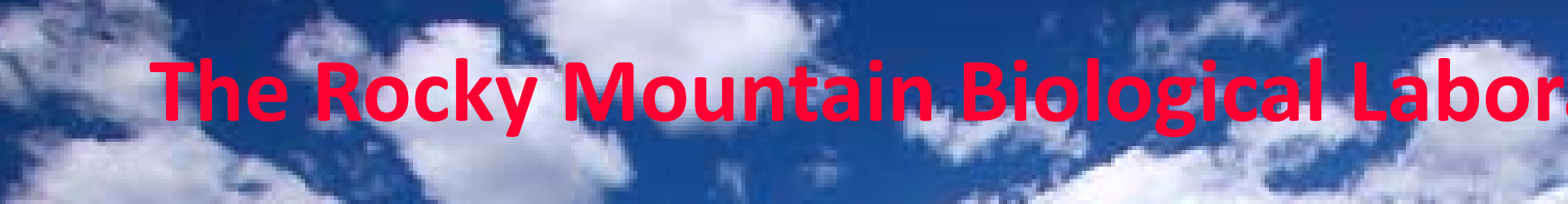

(1)

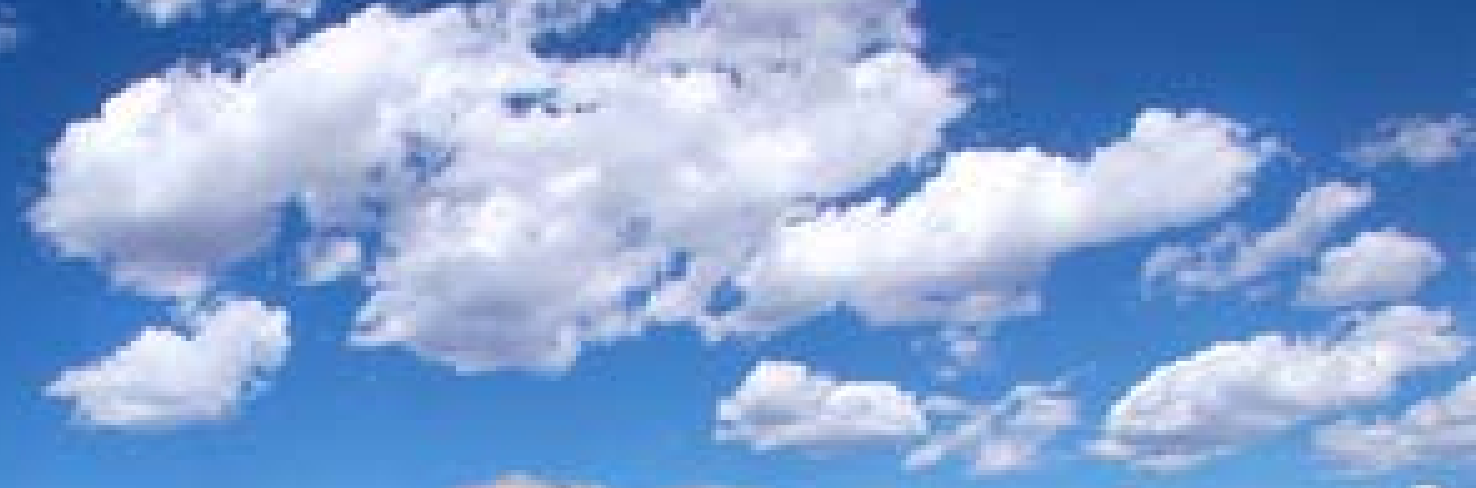

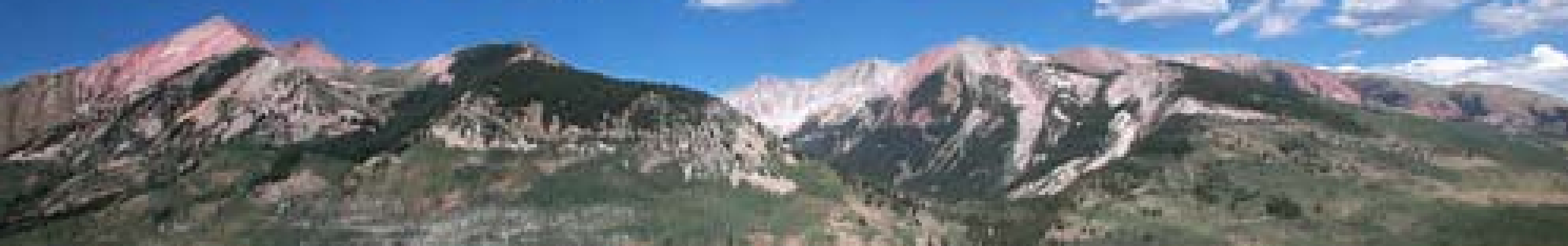

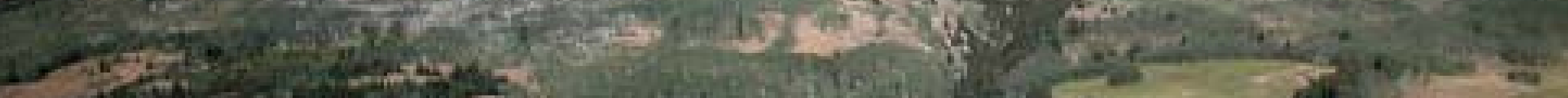

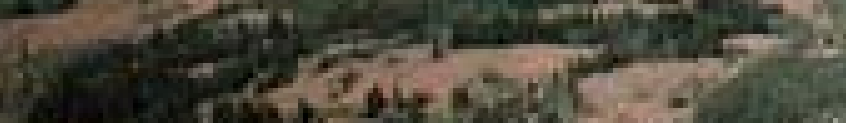

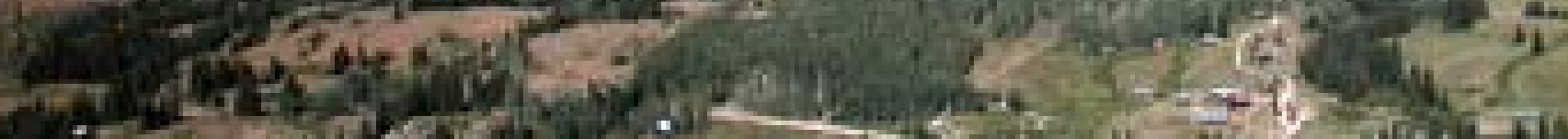

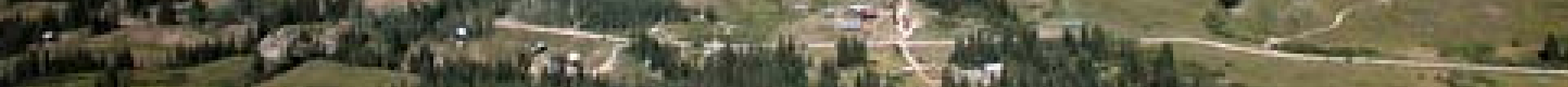

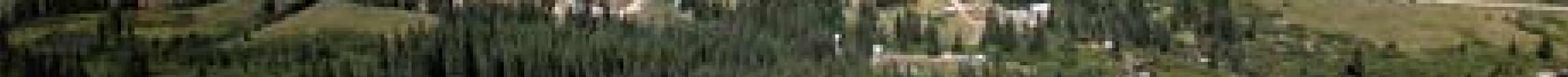

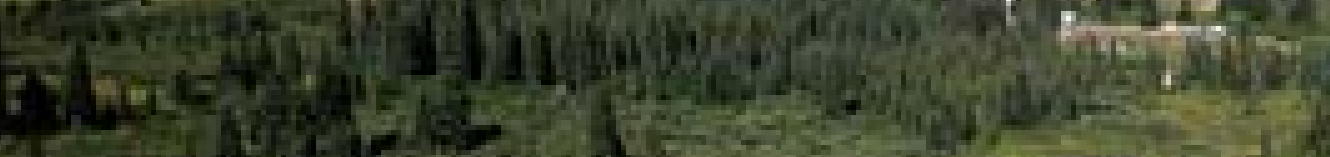

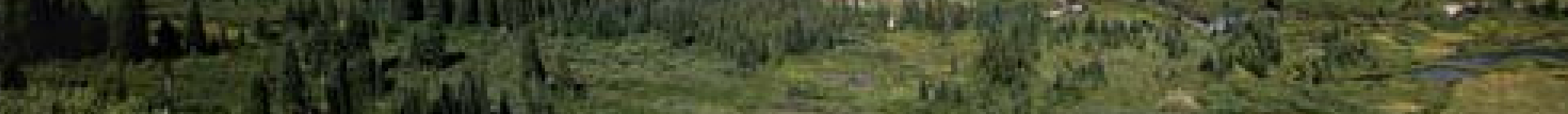

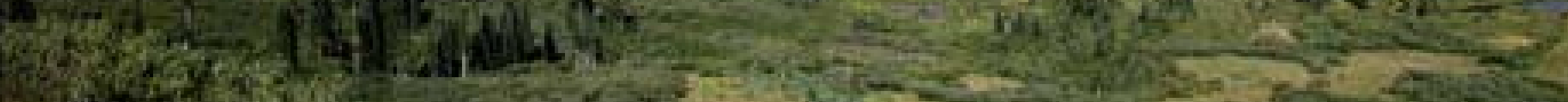
Which

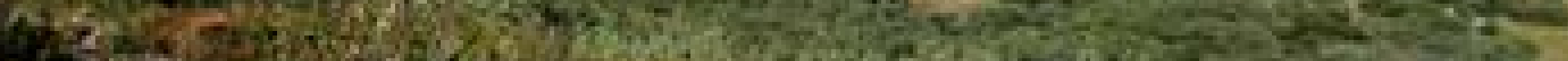




\section{Mean snowfall (since 1975) $=11.1 \mathrm{~m}$ Range $=4.7-16.4 \mathrm{~m}$}

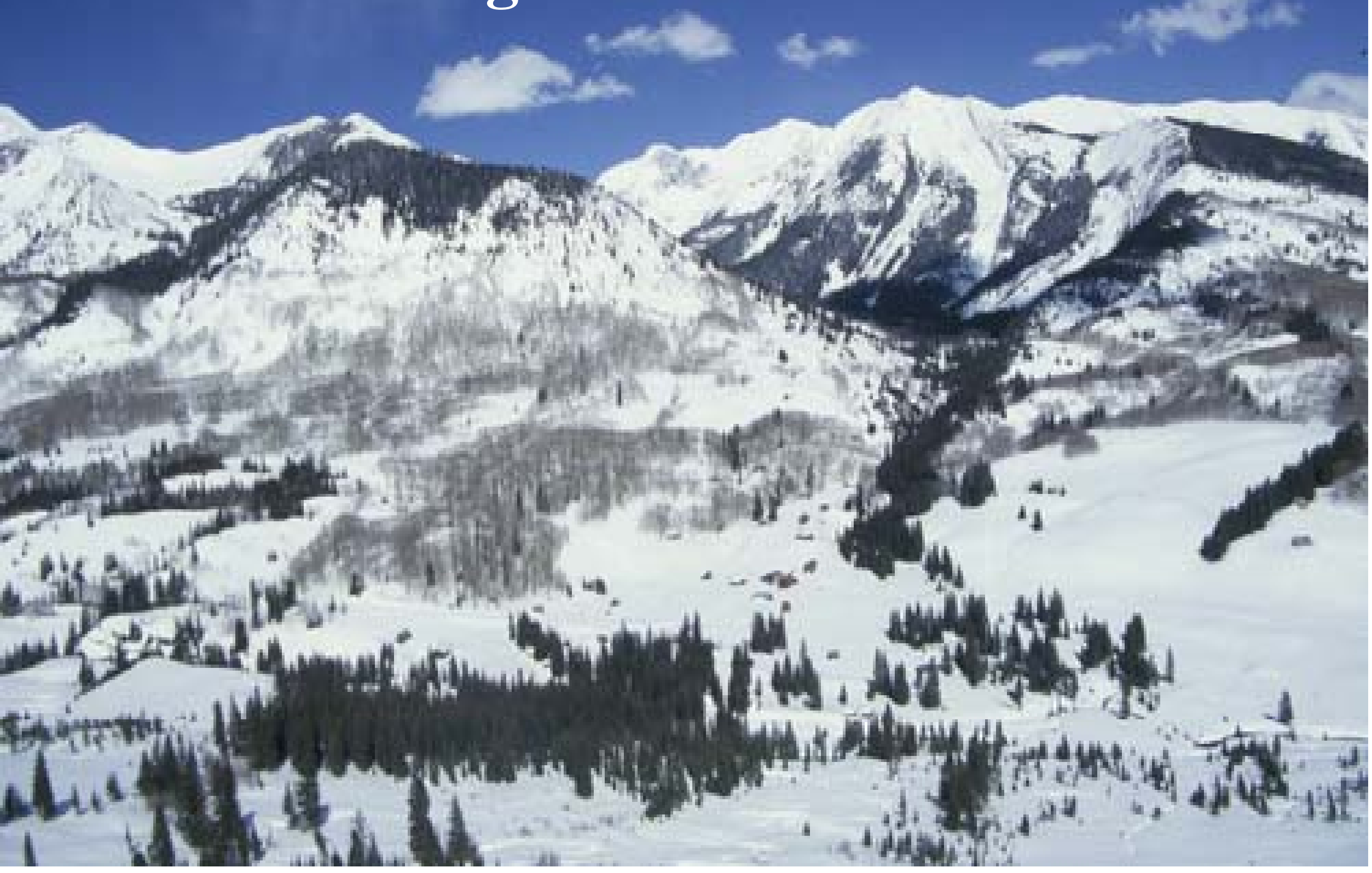




\section{Snowmelt date is a good predictor of flowering time in subalpine wildflowers}
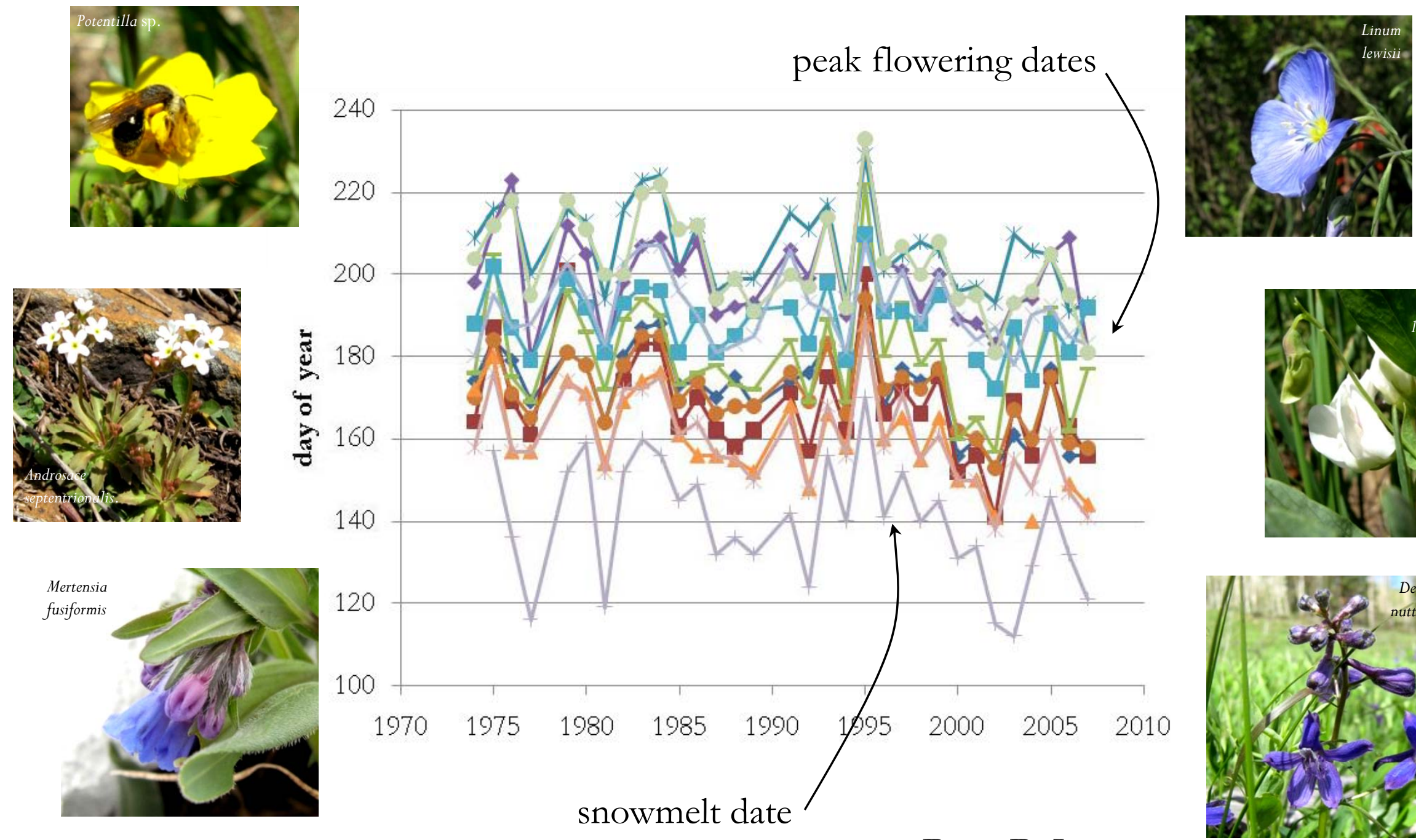

Data: D. Inouye
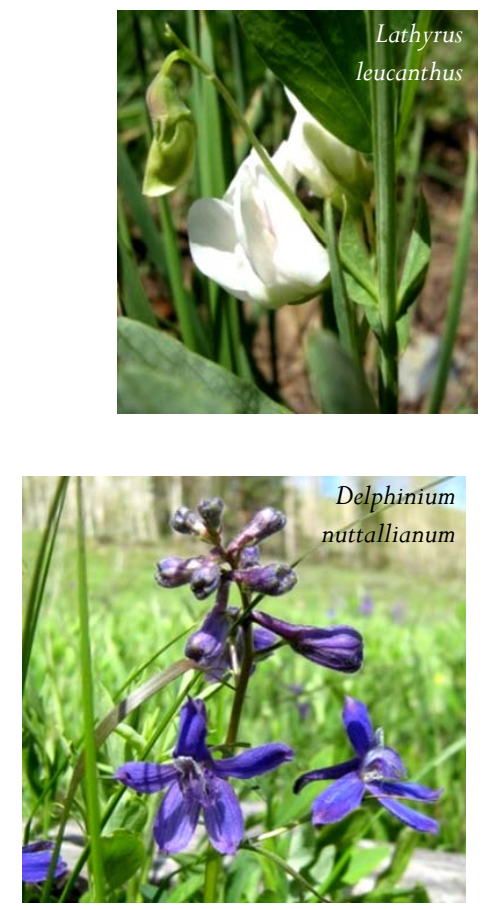

Slide by Jessica Forrest 


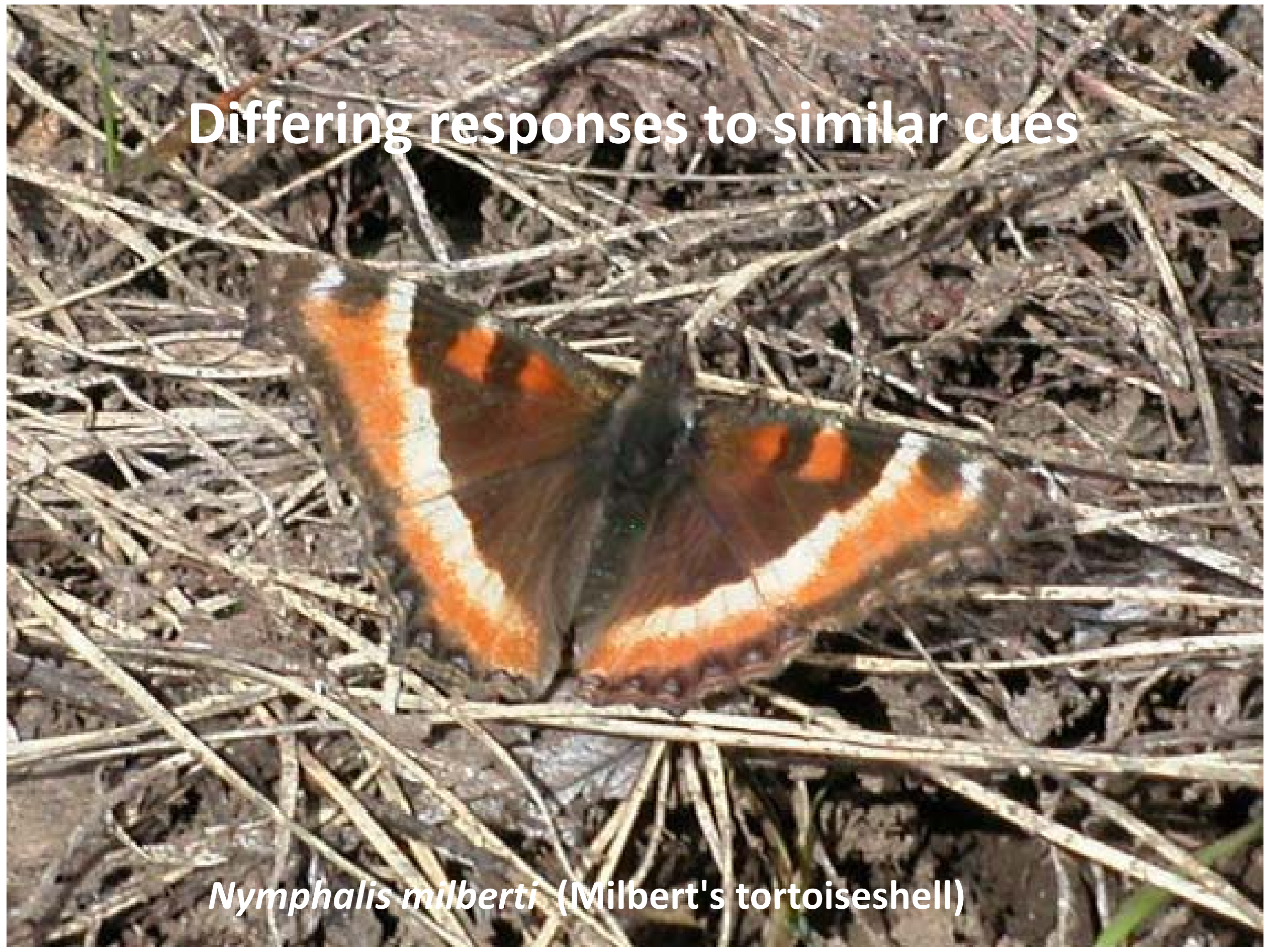




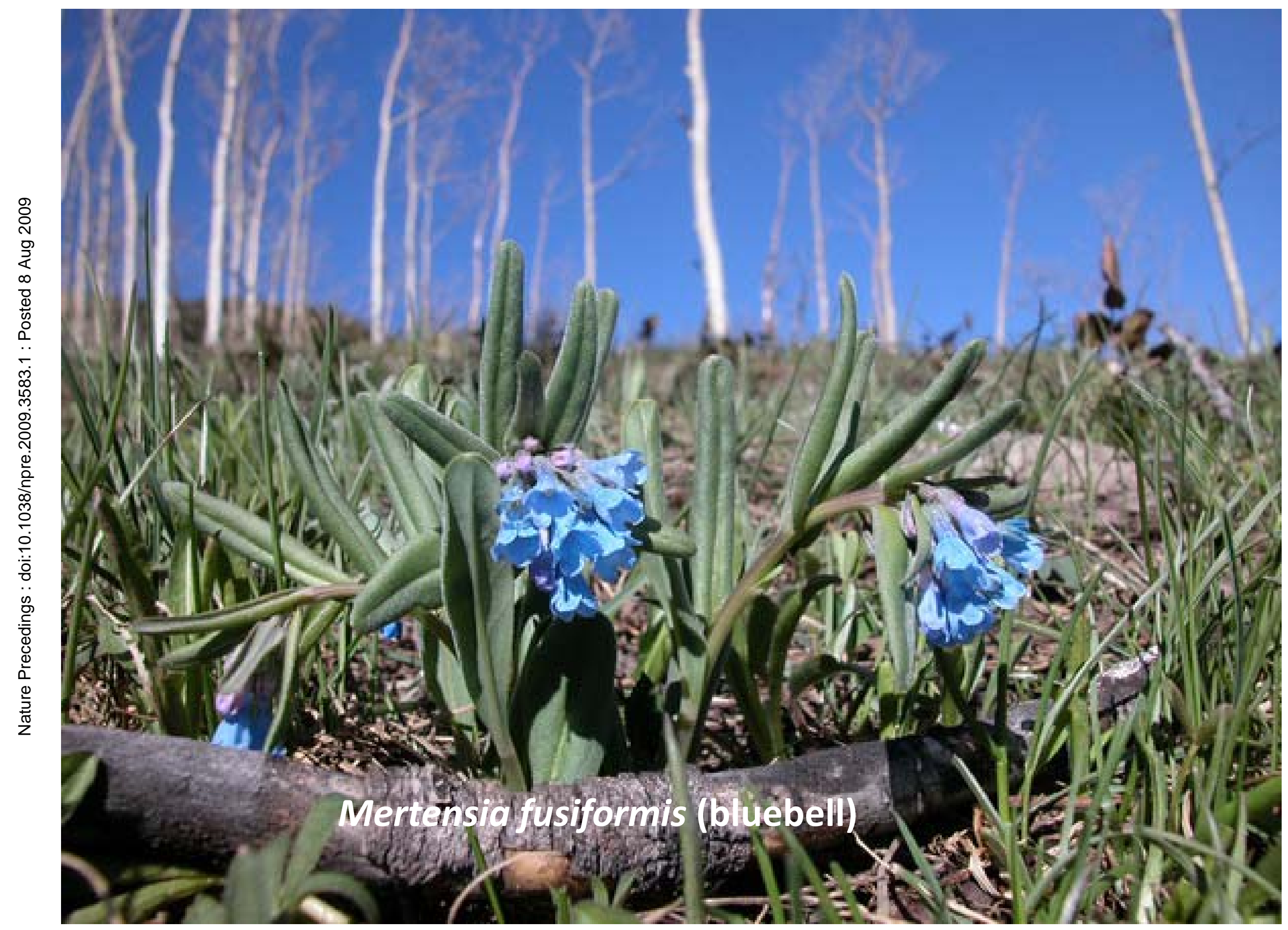




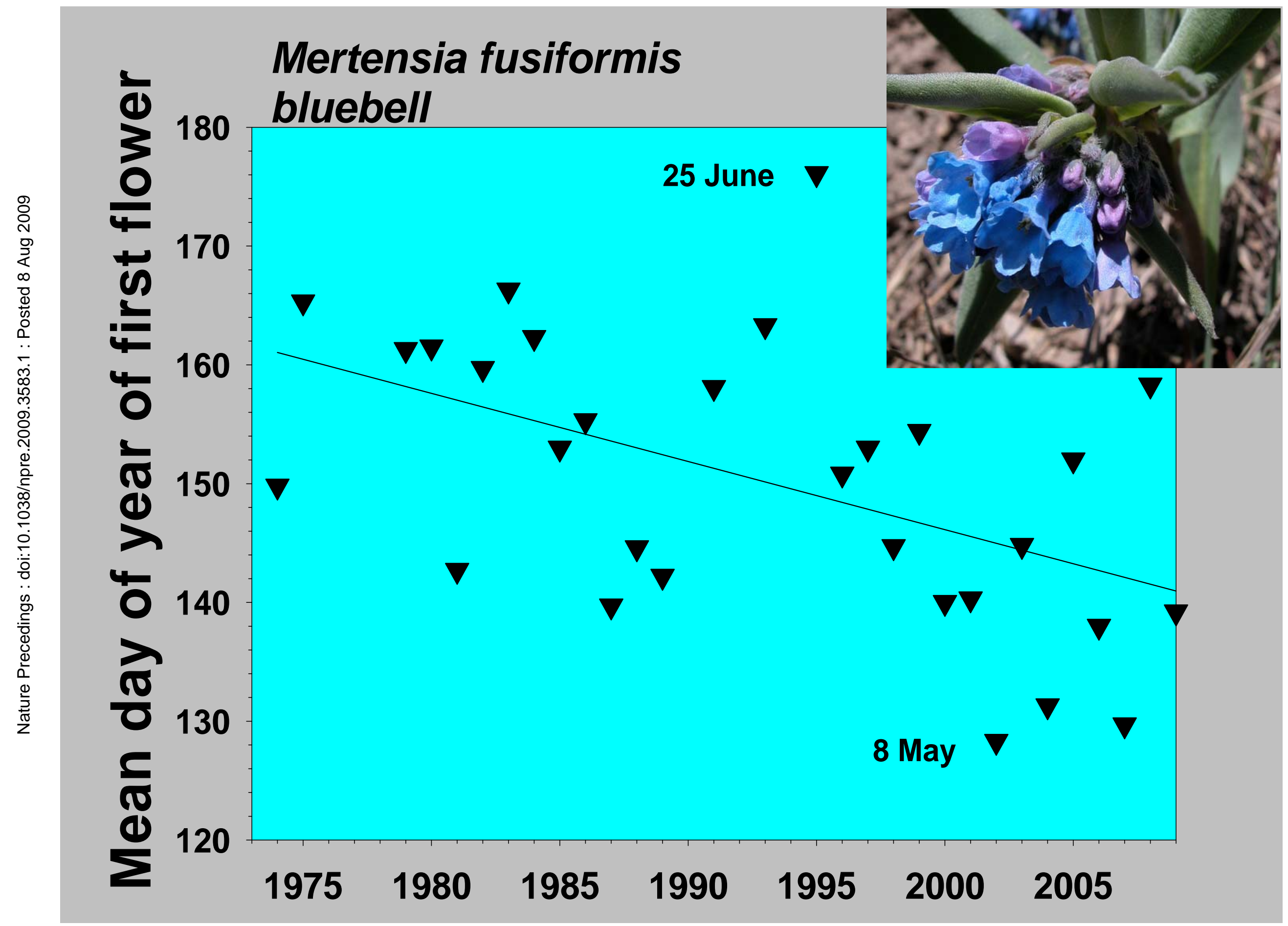




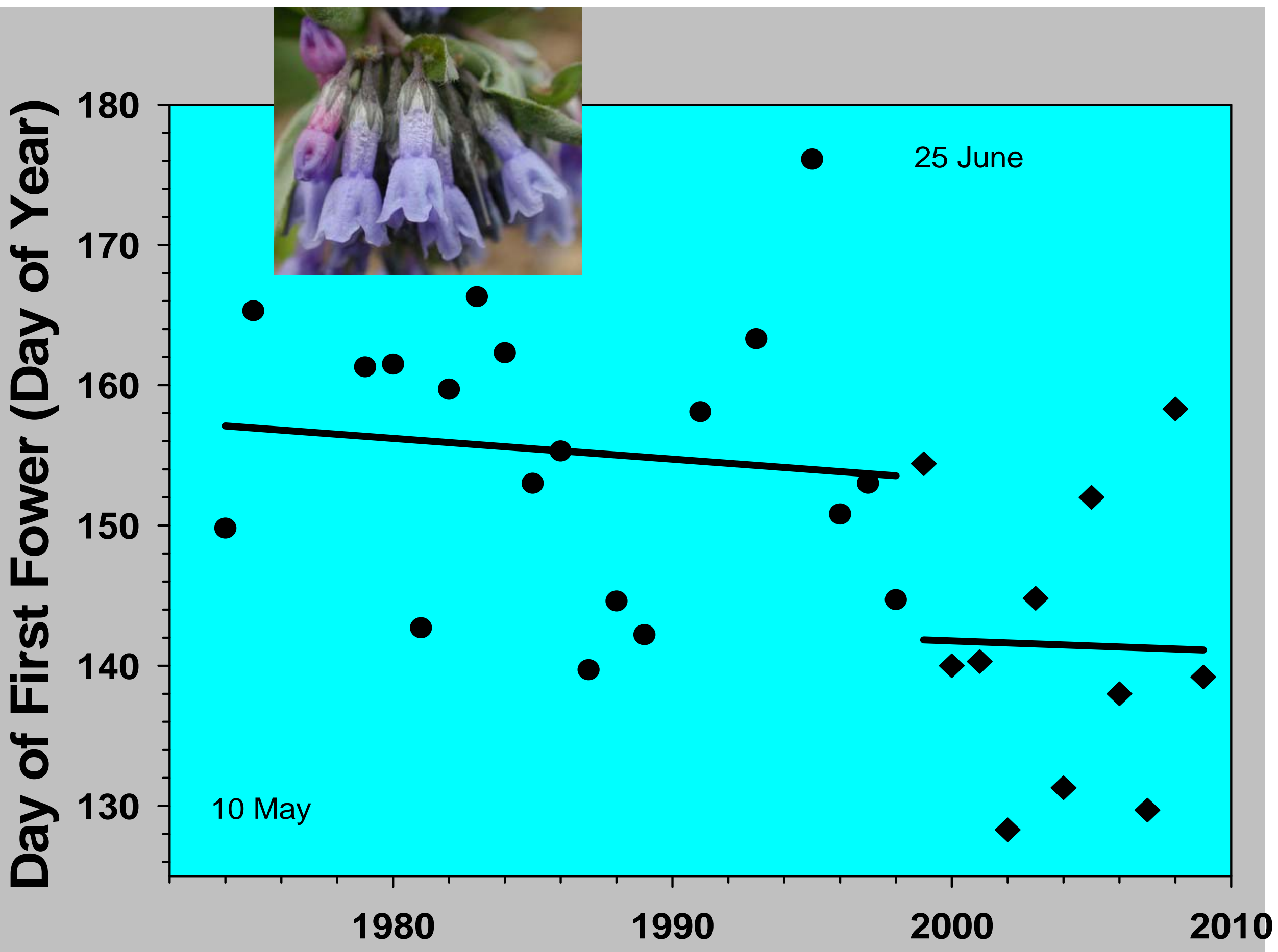




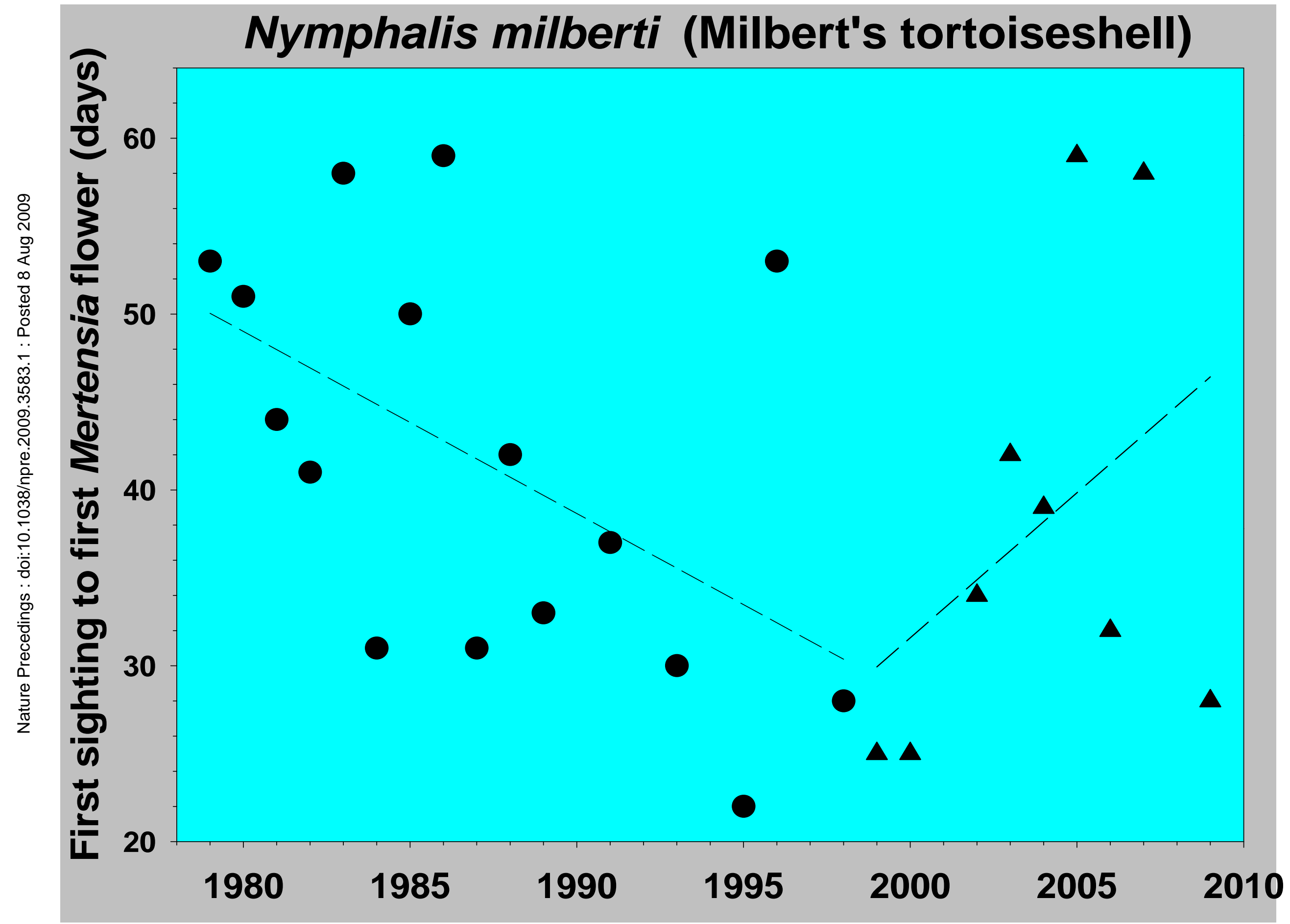




\section{Links between phenology and abundance}

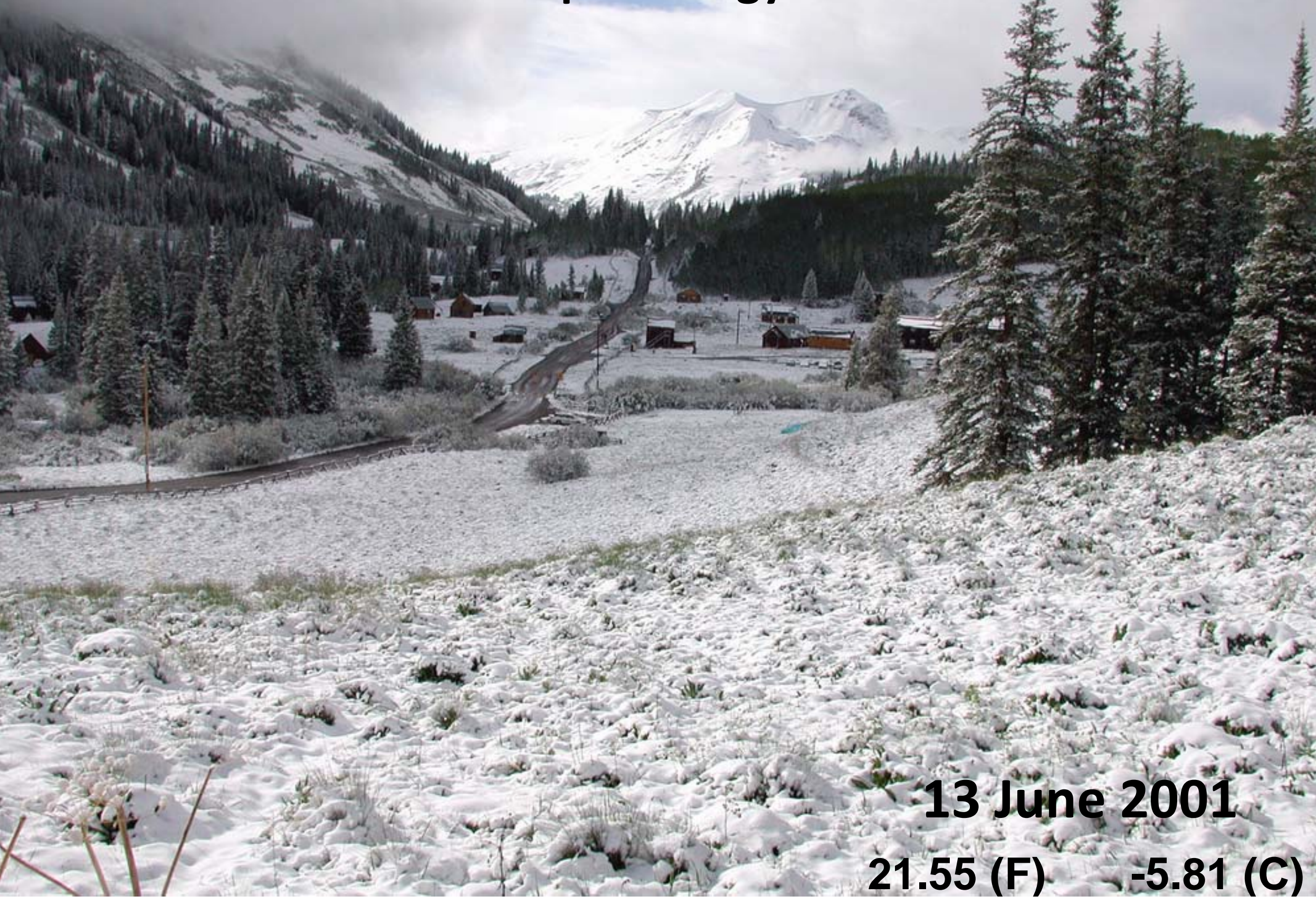




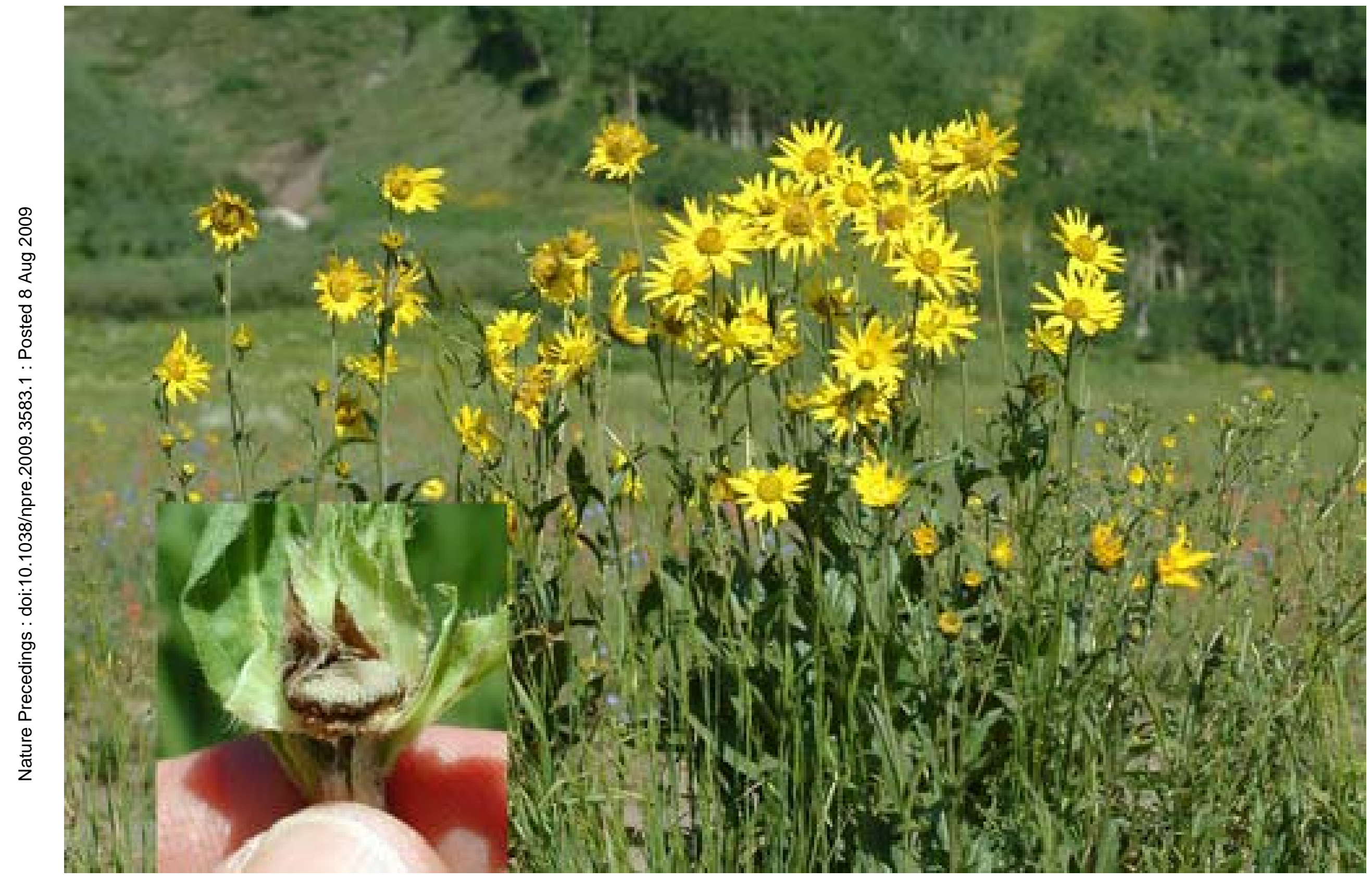

Flowers and a frost-killed bud of Helianthella quinquenervis at RMBL 


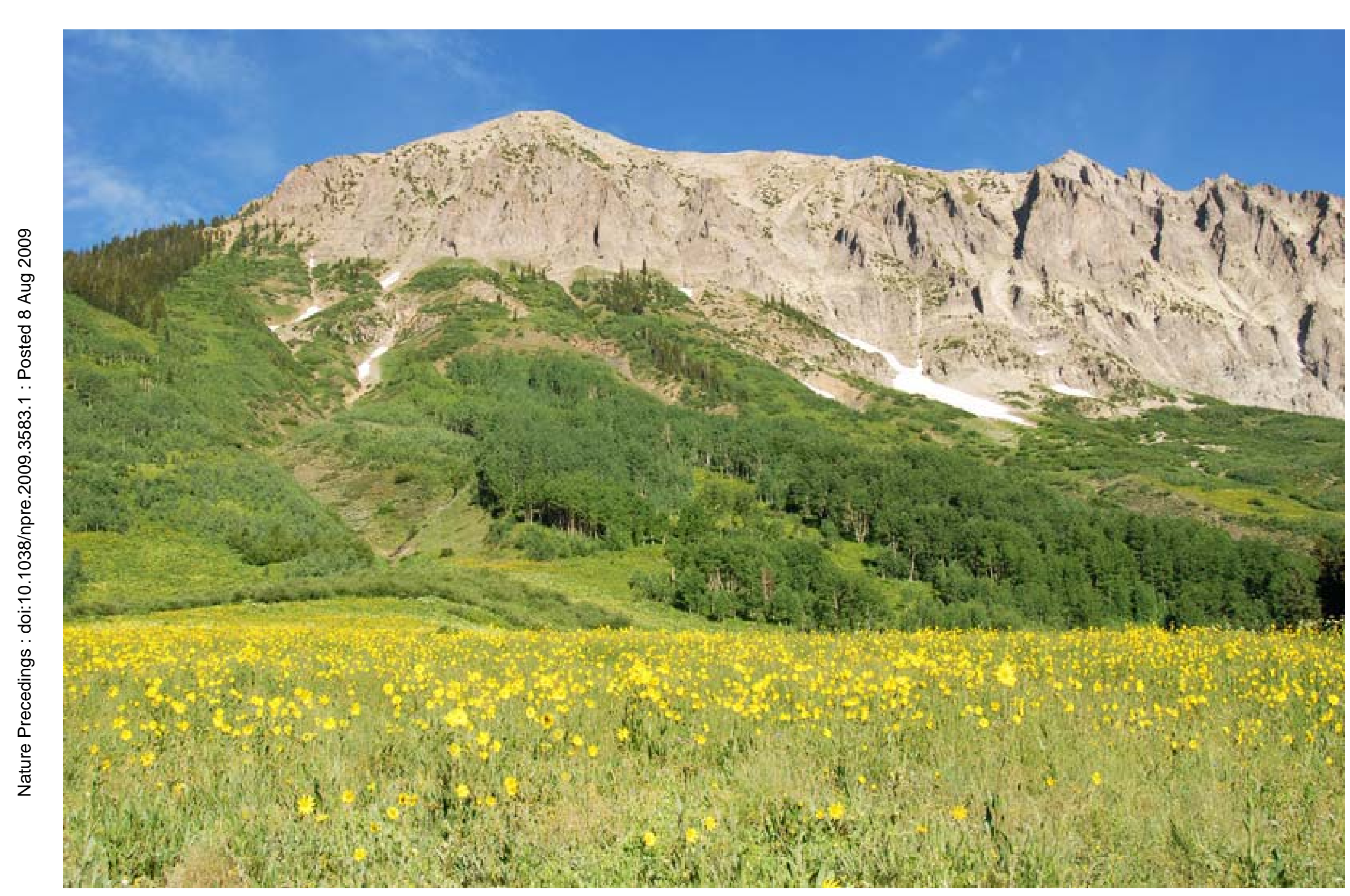

Helianthella quinquenervis - Aspen sunflower (good flowering year) 


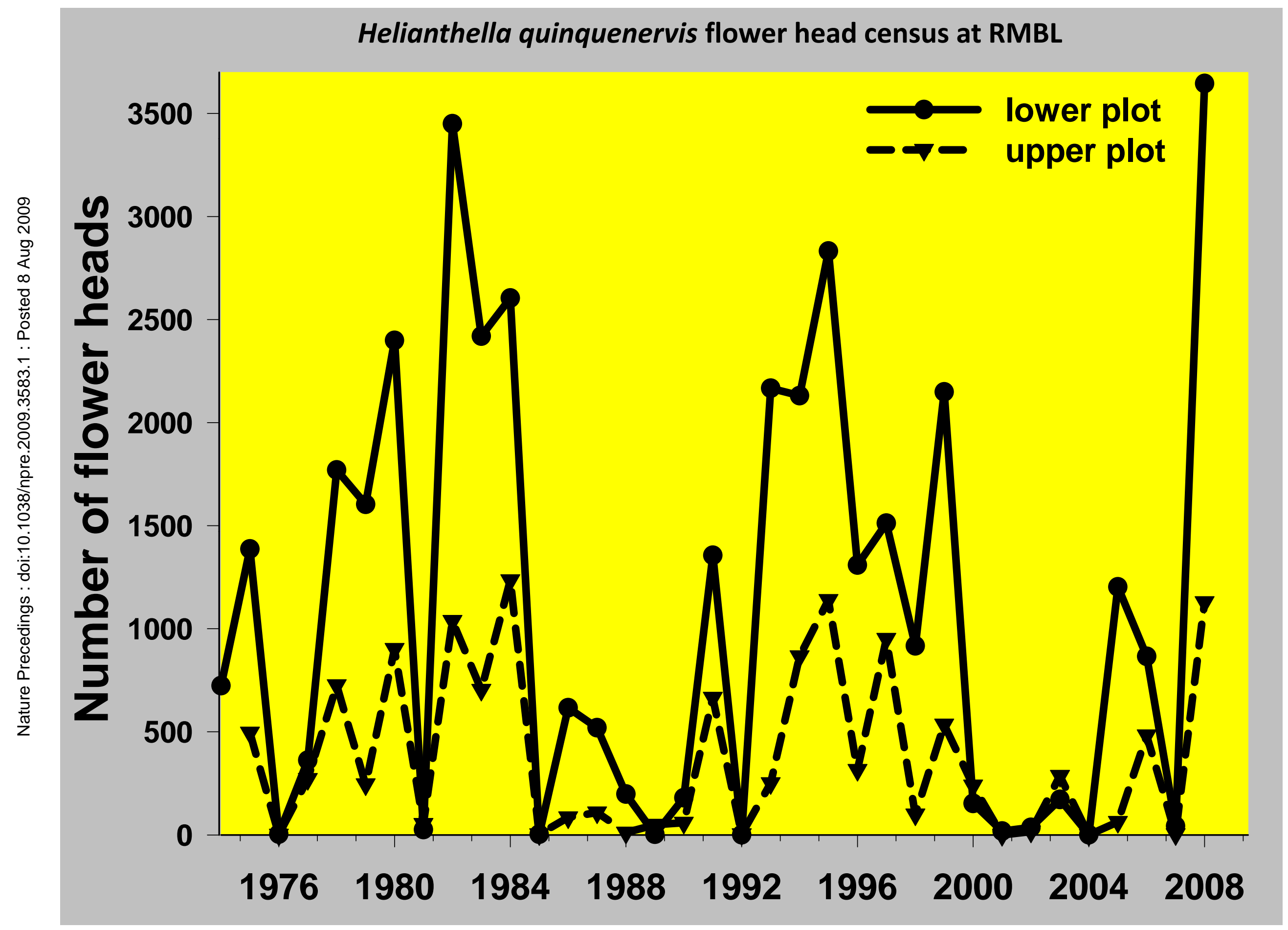




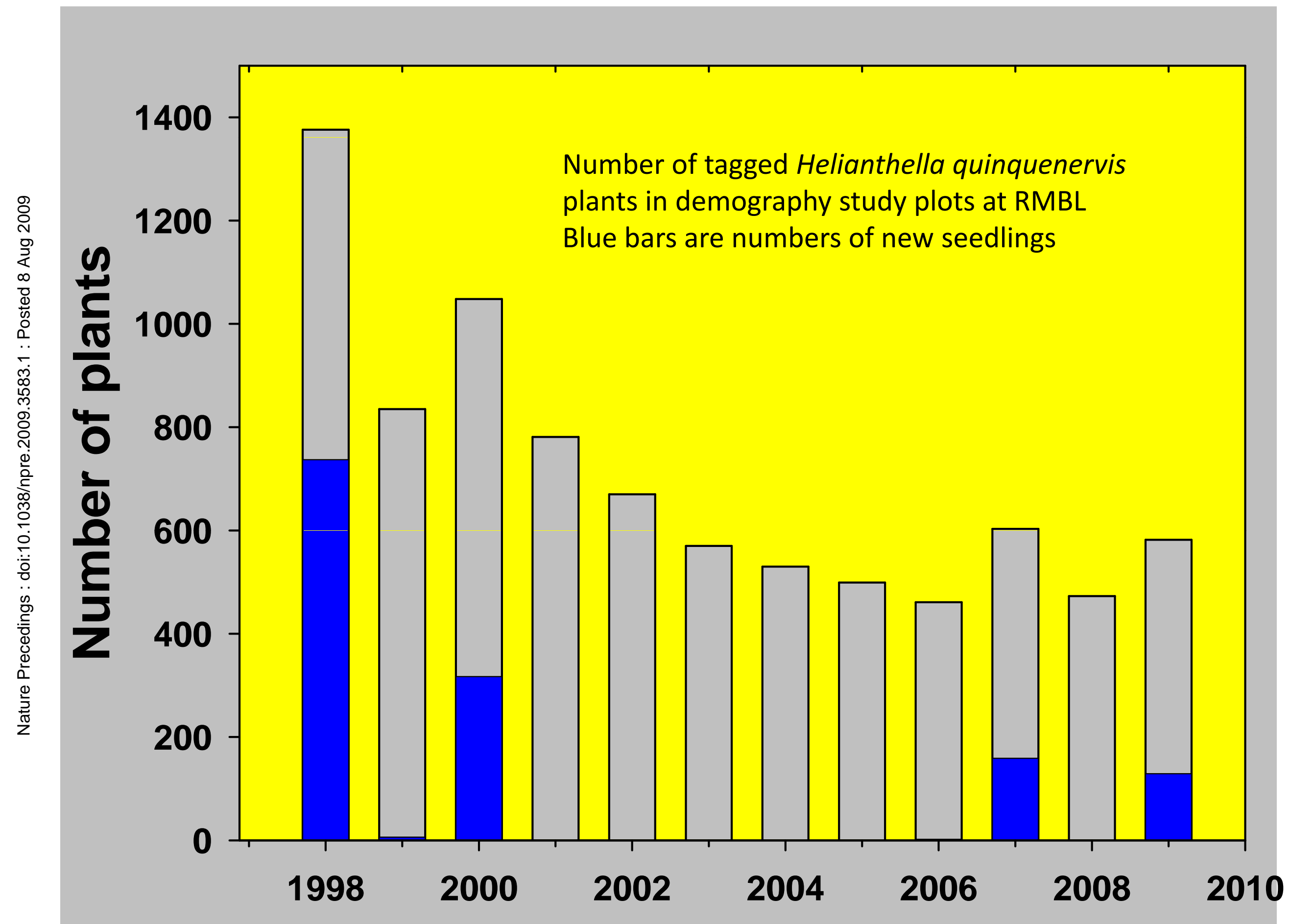




\section{Delphinium barbeyi}

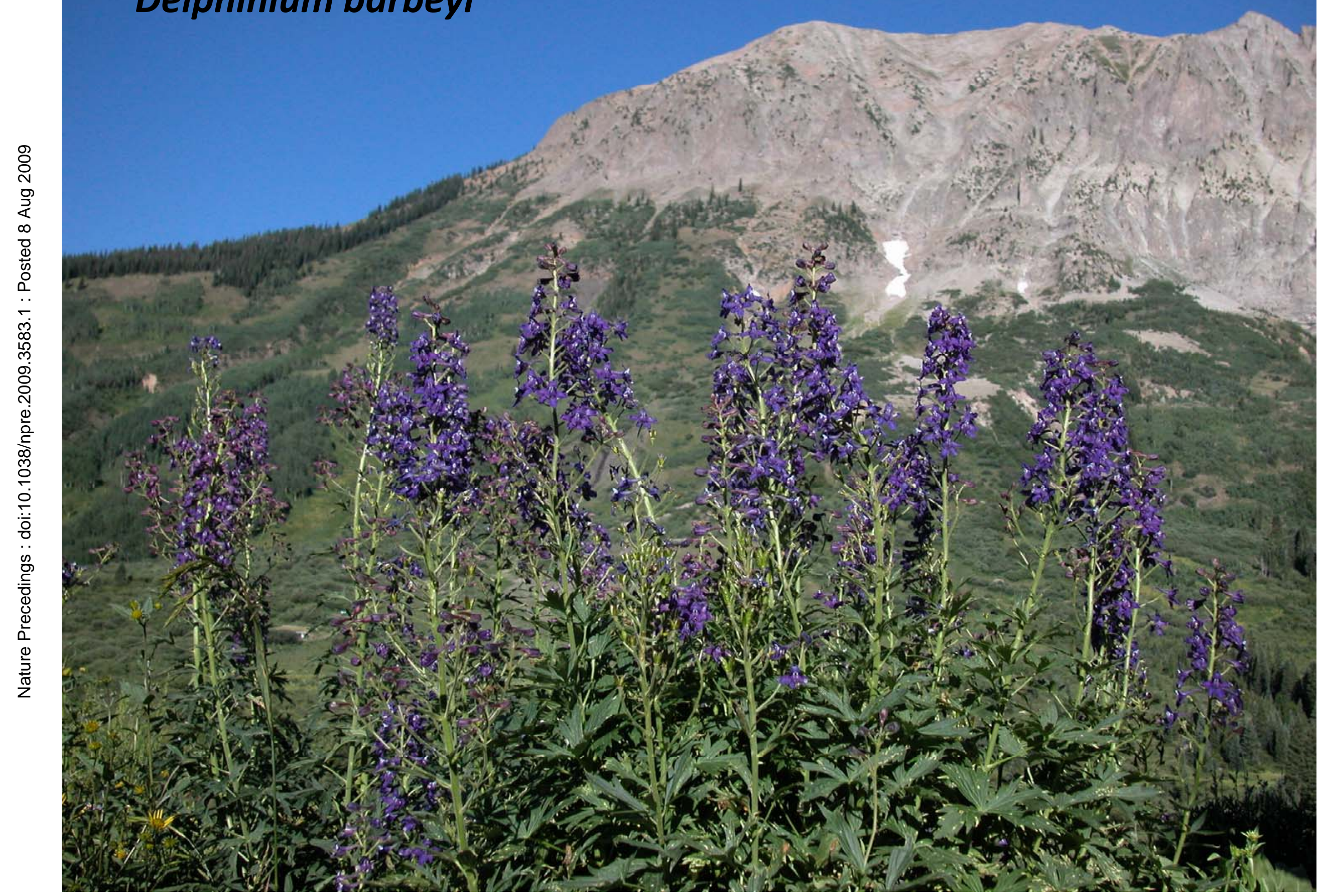




\section{Frost-killed buds of Delphinium barbeyi}

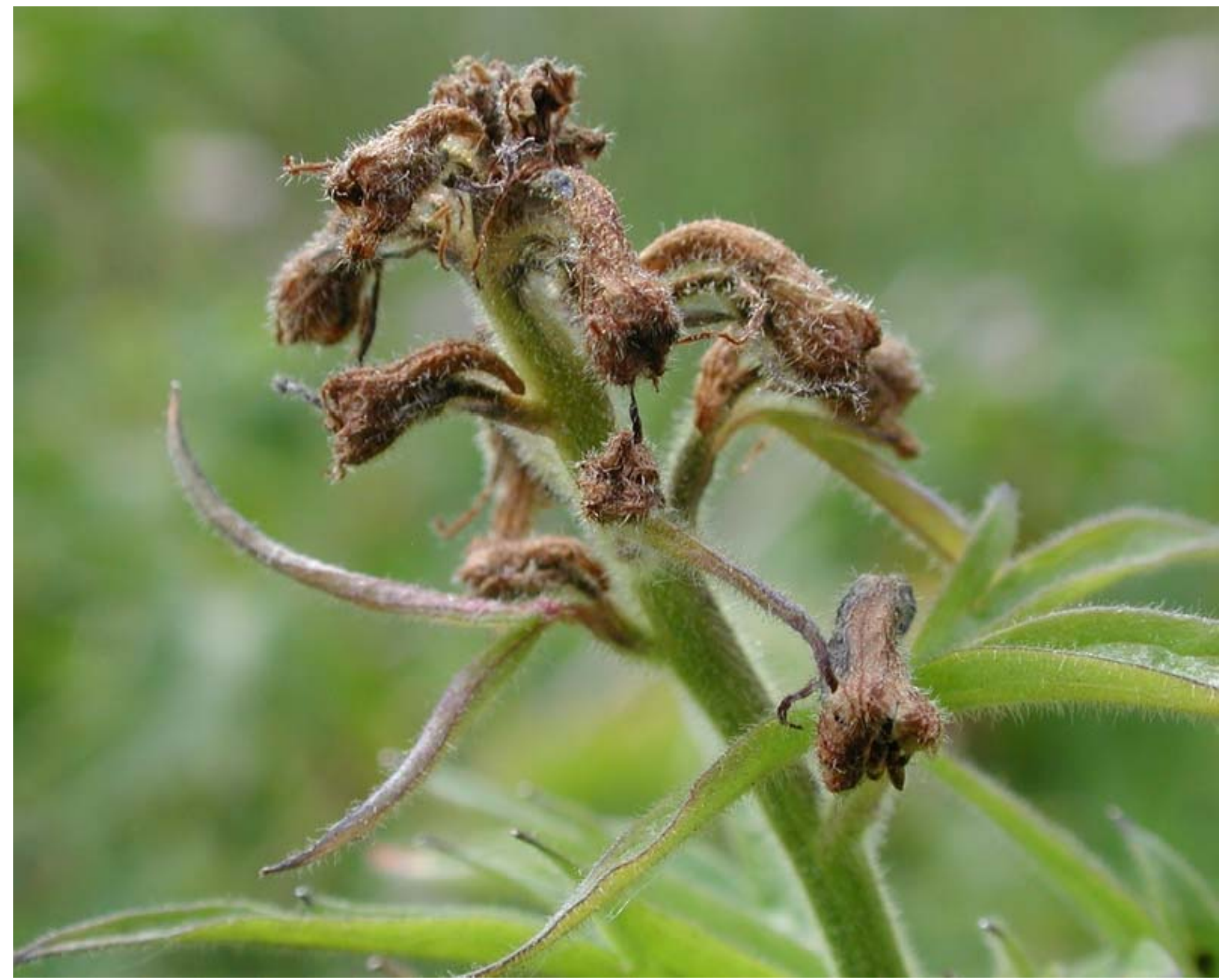




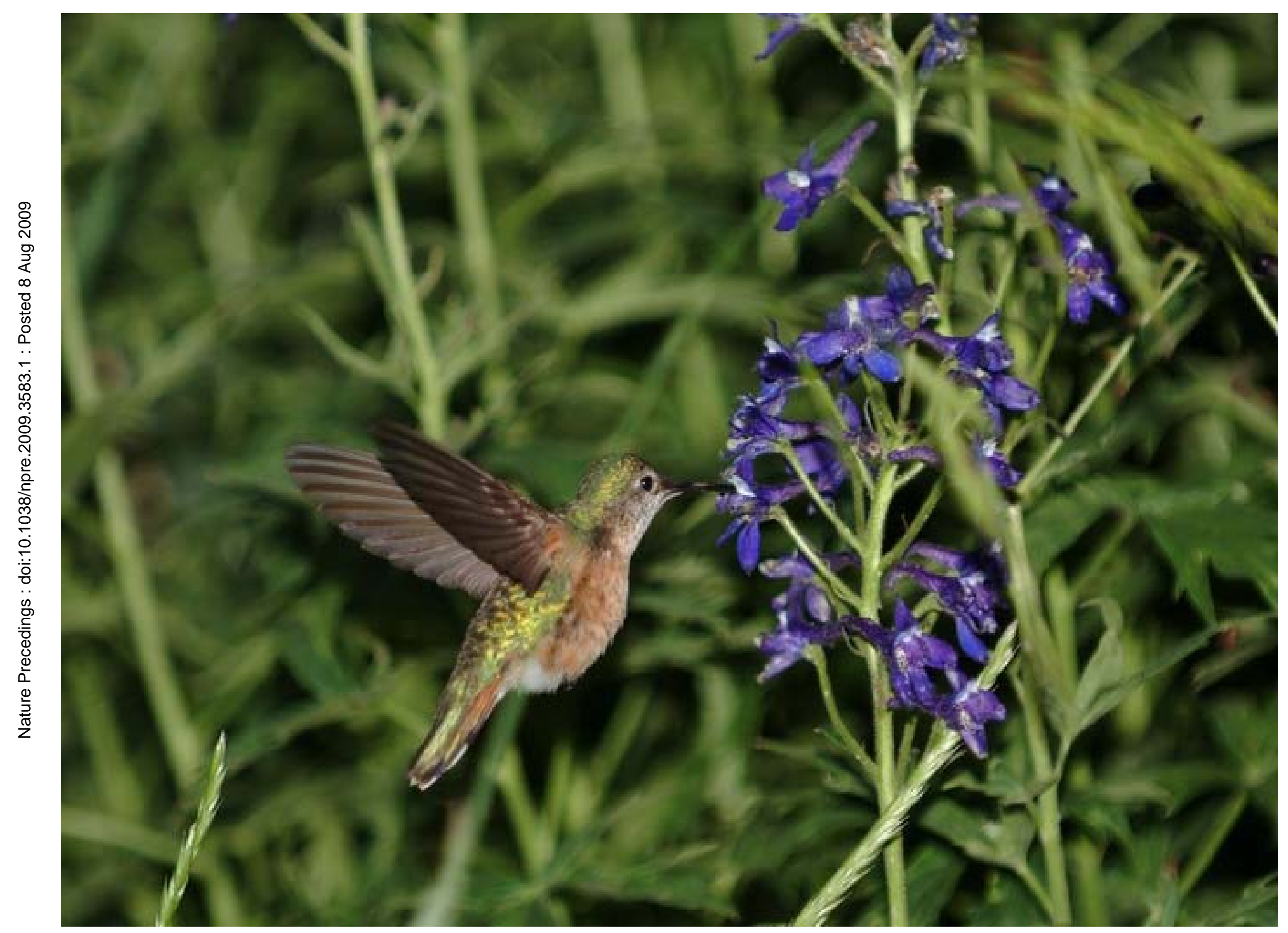




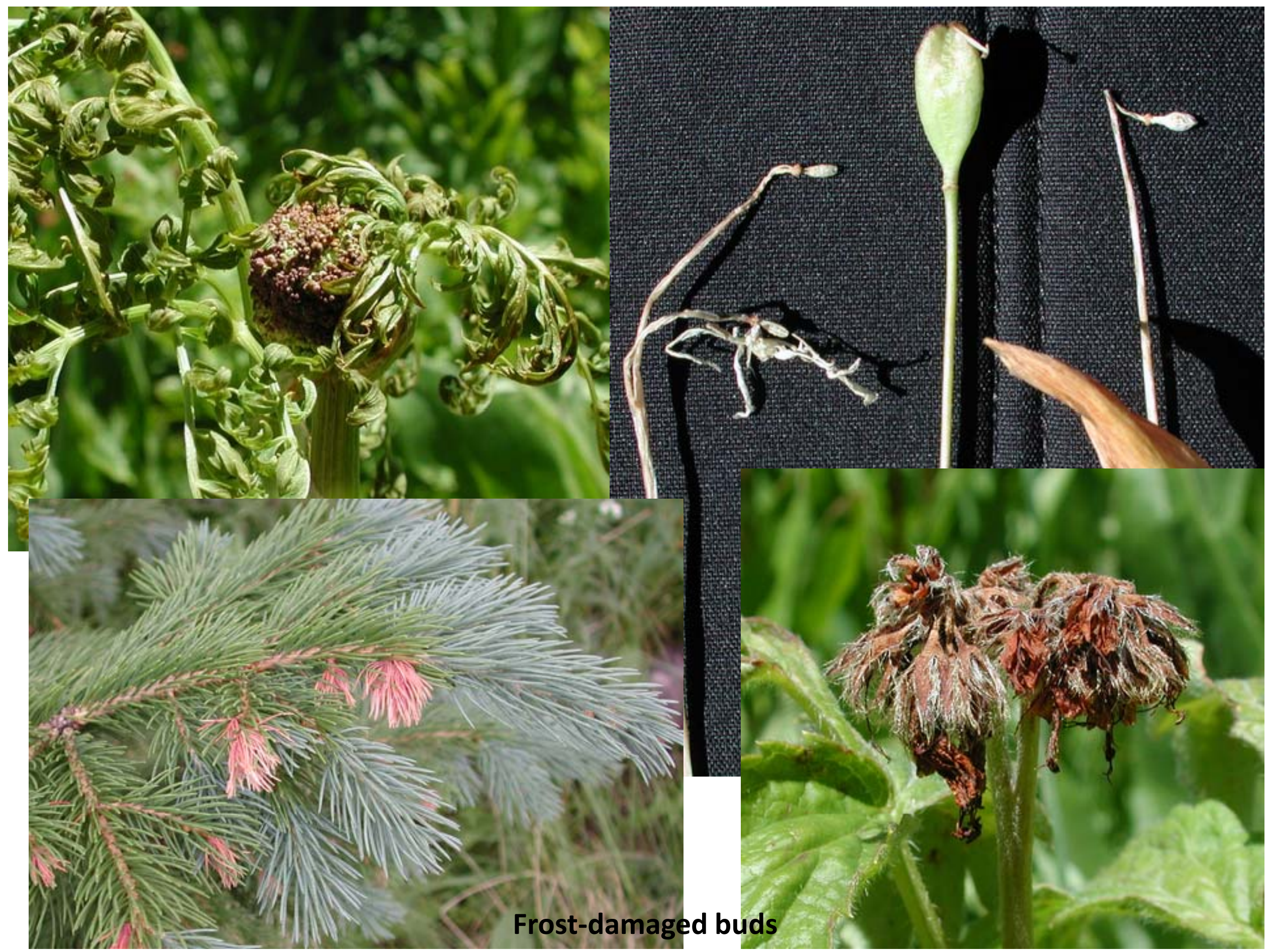




\section{Variation in pollinator populations}
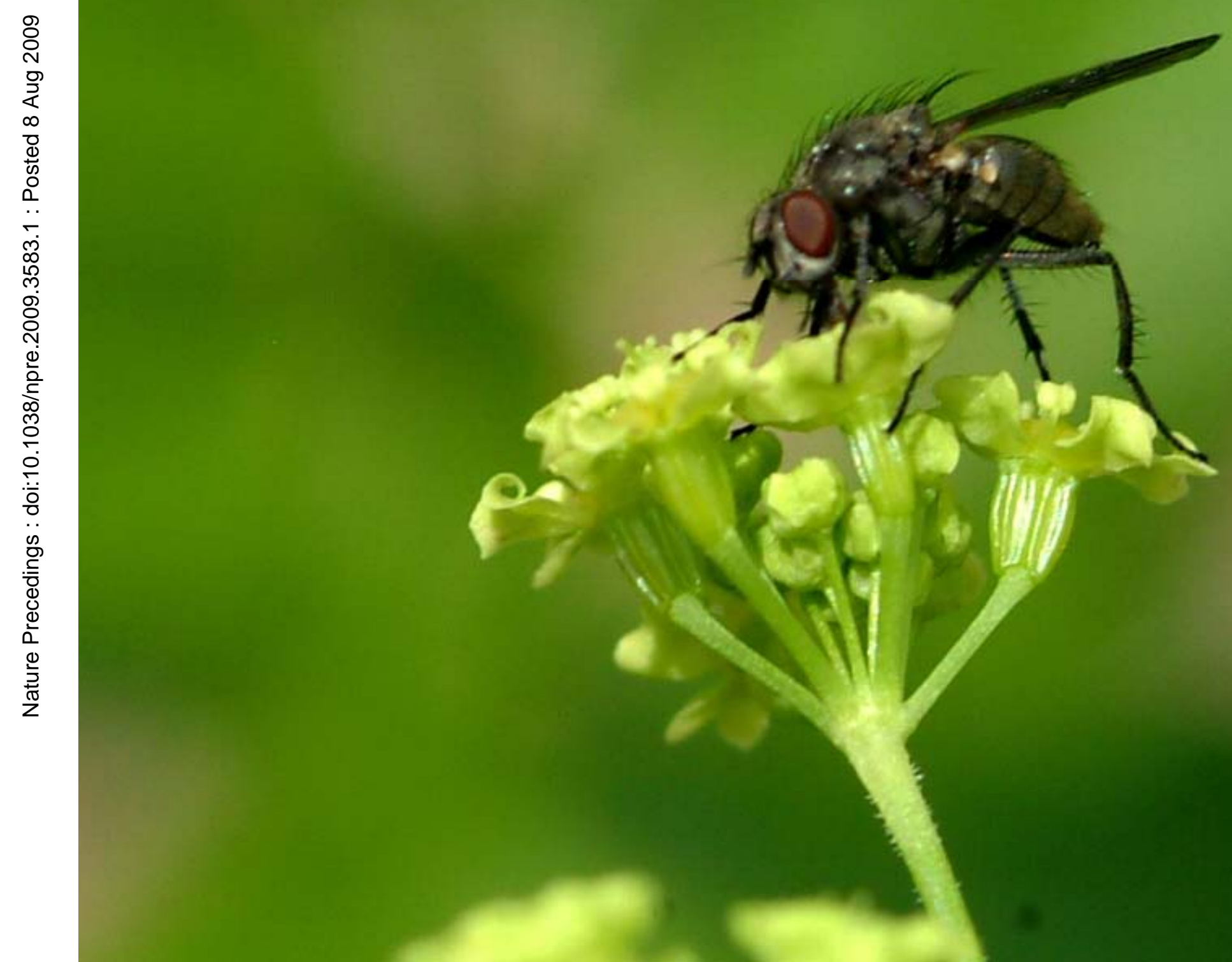


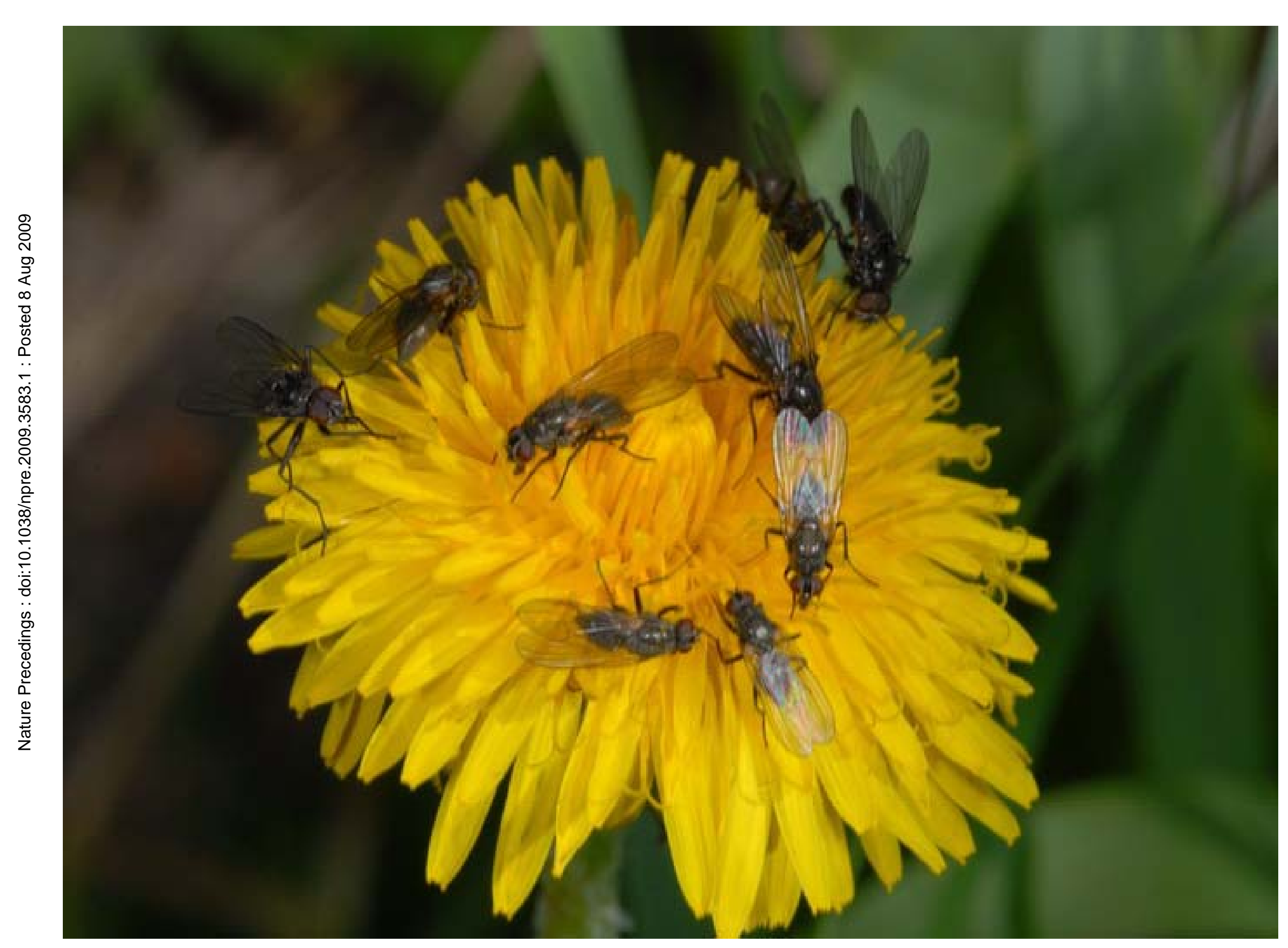




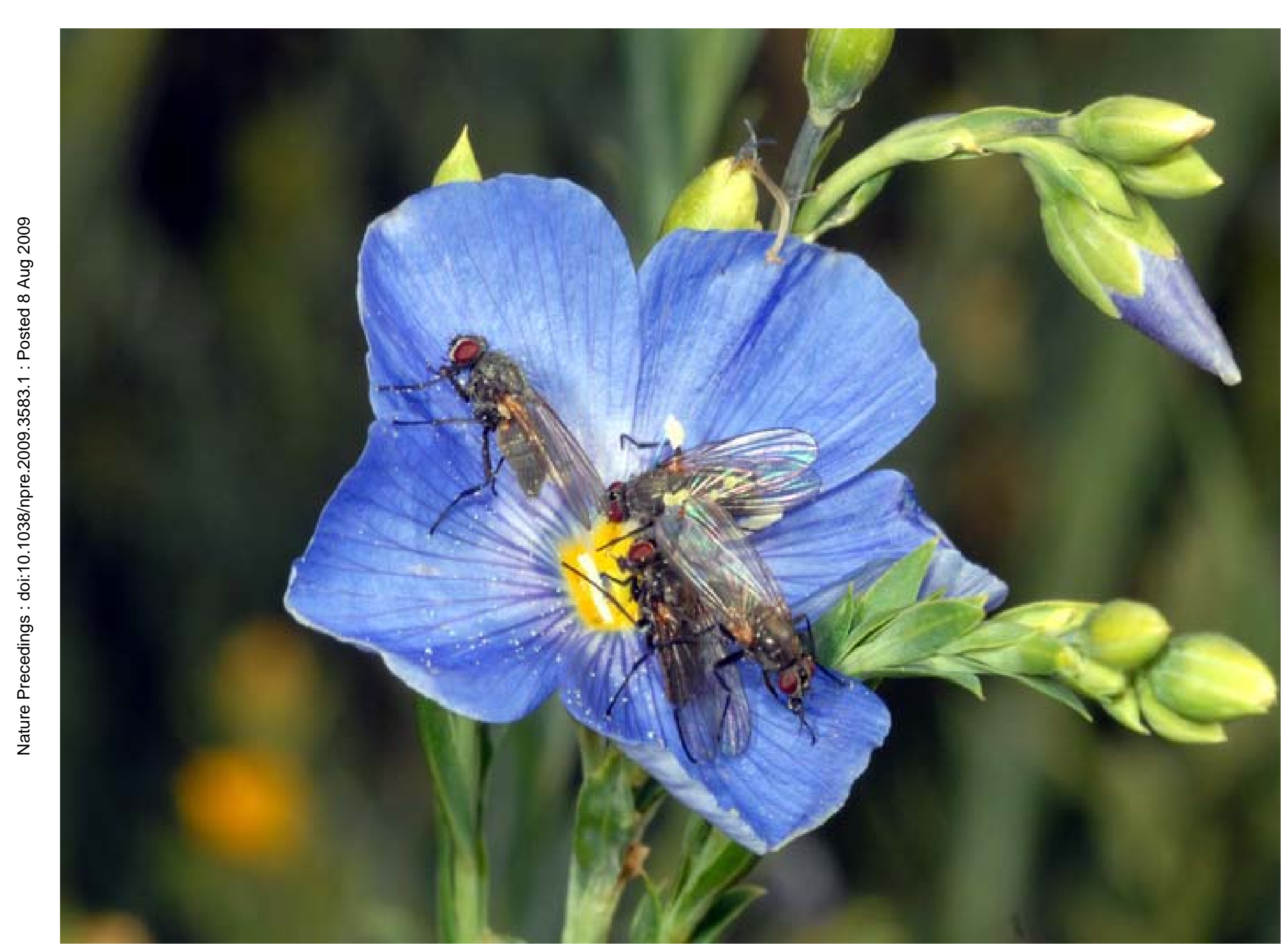




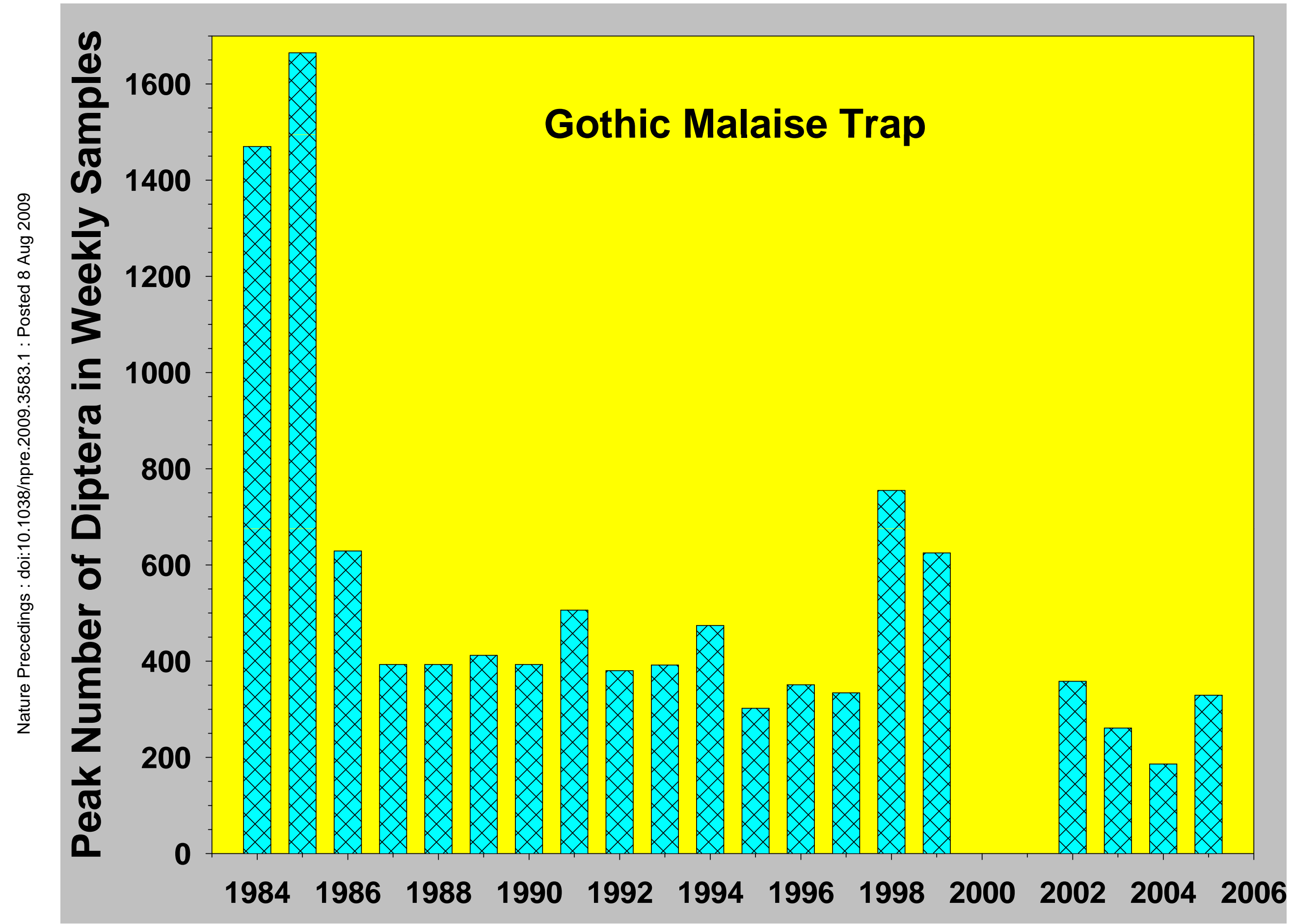




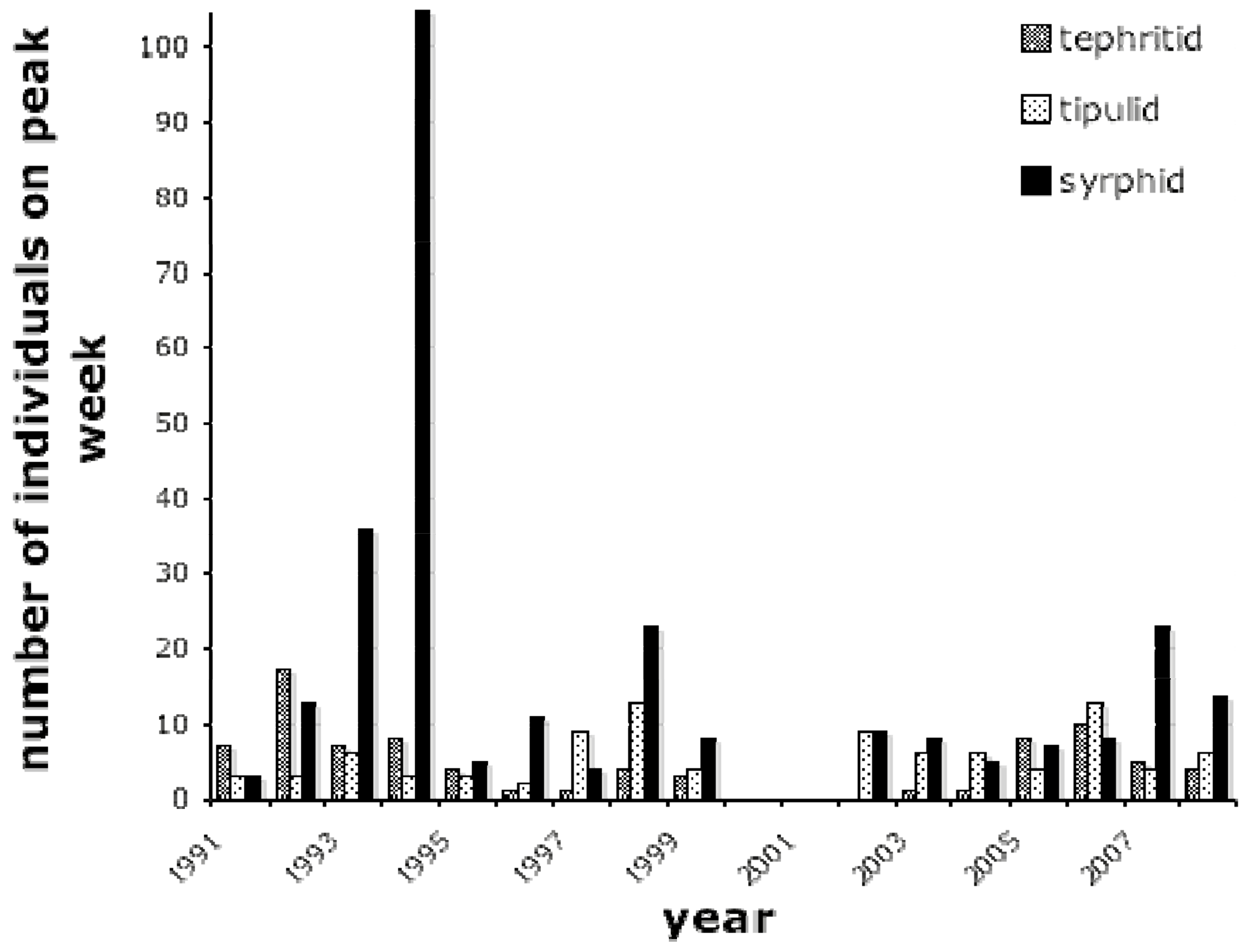




\section{Are pollinators being affected?}

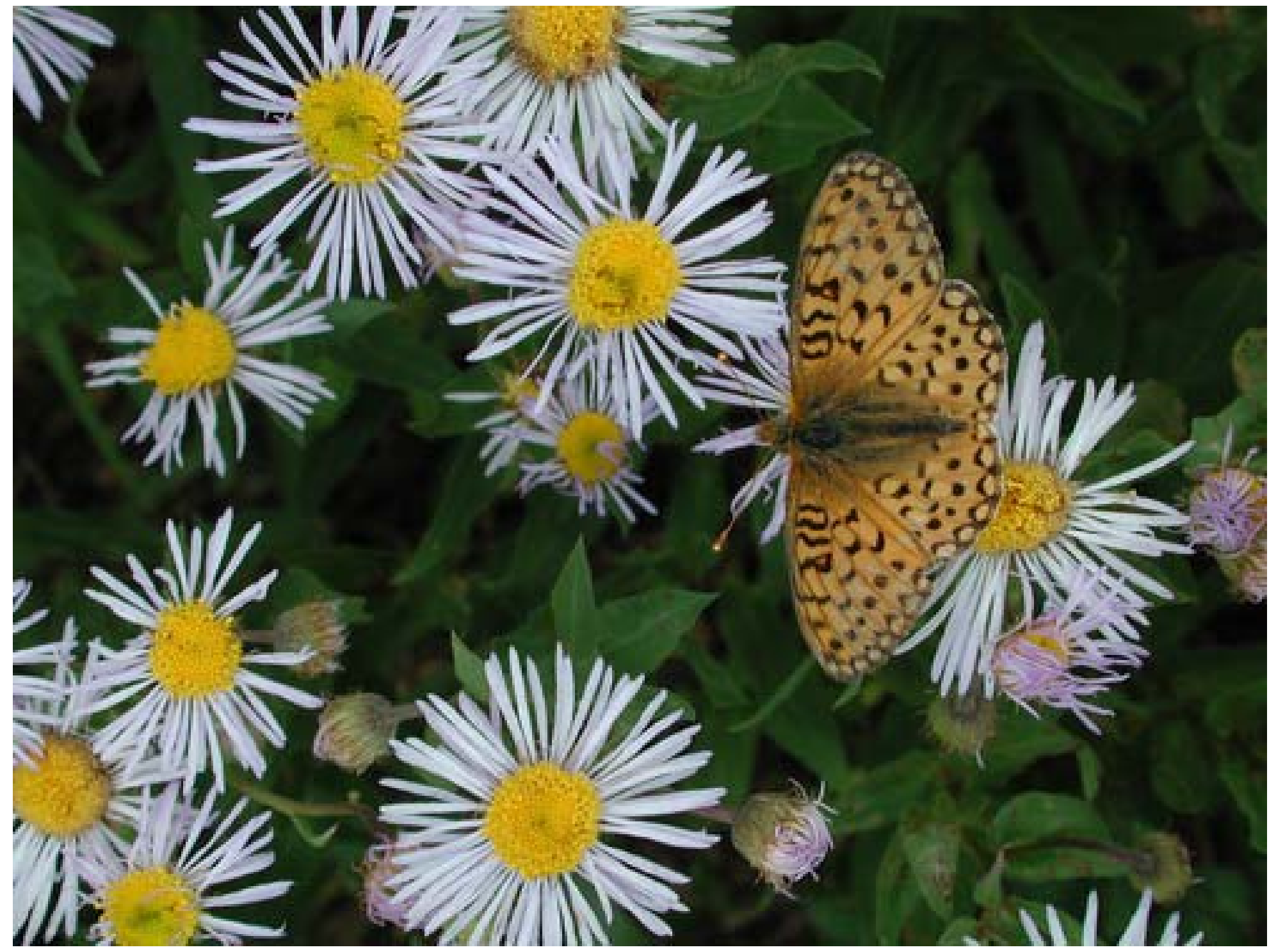

Speyeria mormonia and Erigeron speciosus 


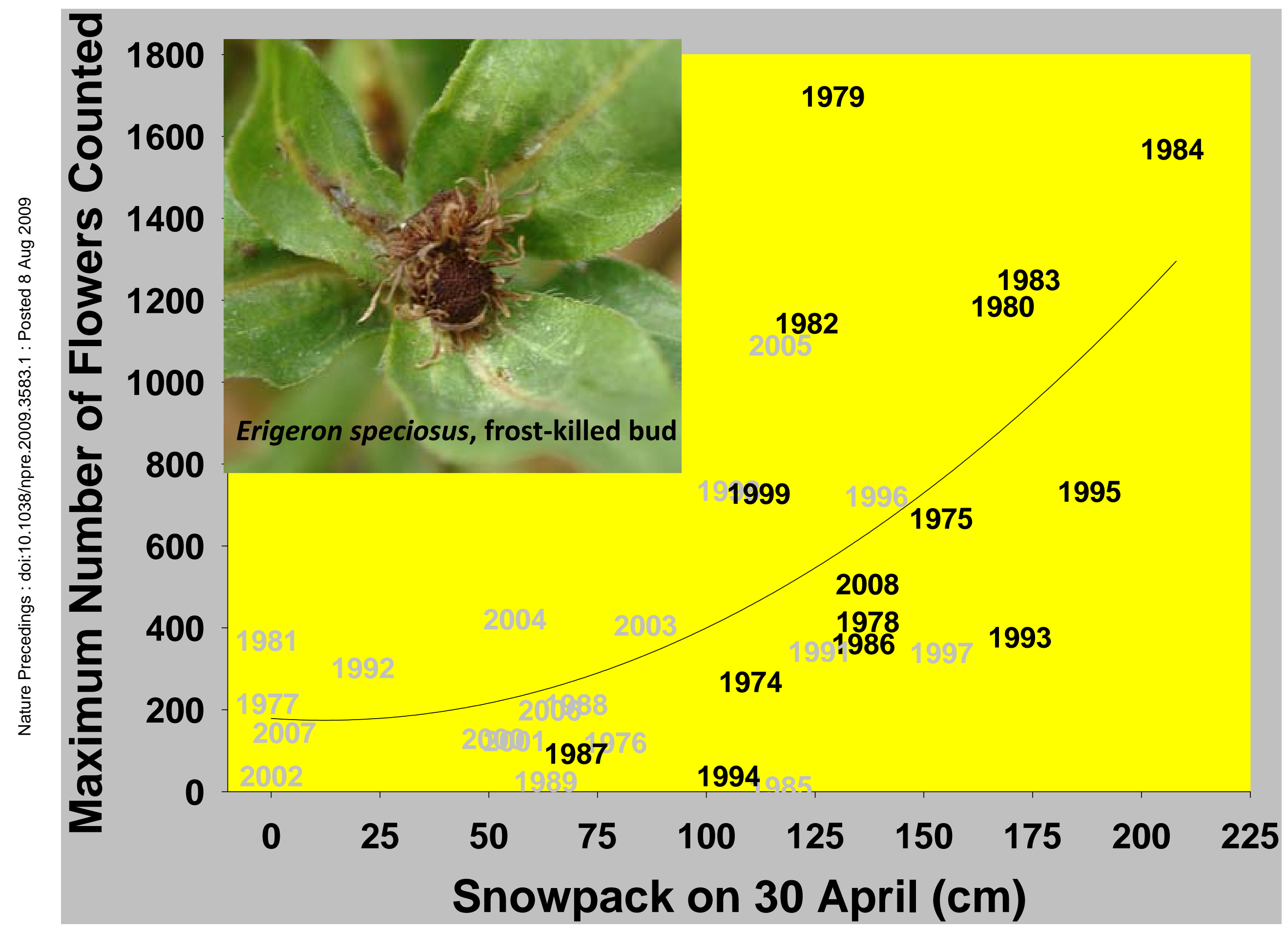




\section{The Erigeron - Speyeria story}

- Decreasing snowpack

- Warmer springs

- Earlier snowmelt

- Earlier development of (frost-sensitive) buds

- Increased incidence of frost damage

- Fewer flowers (less nectar) for butterflies

- Fewer butterflies 


\section{Range changes}

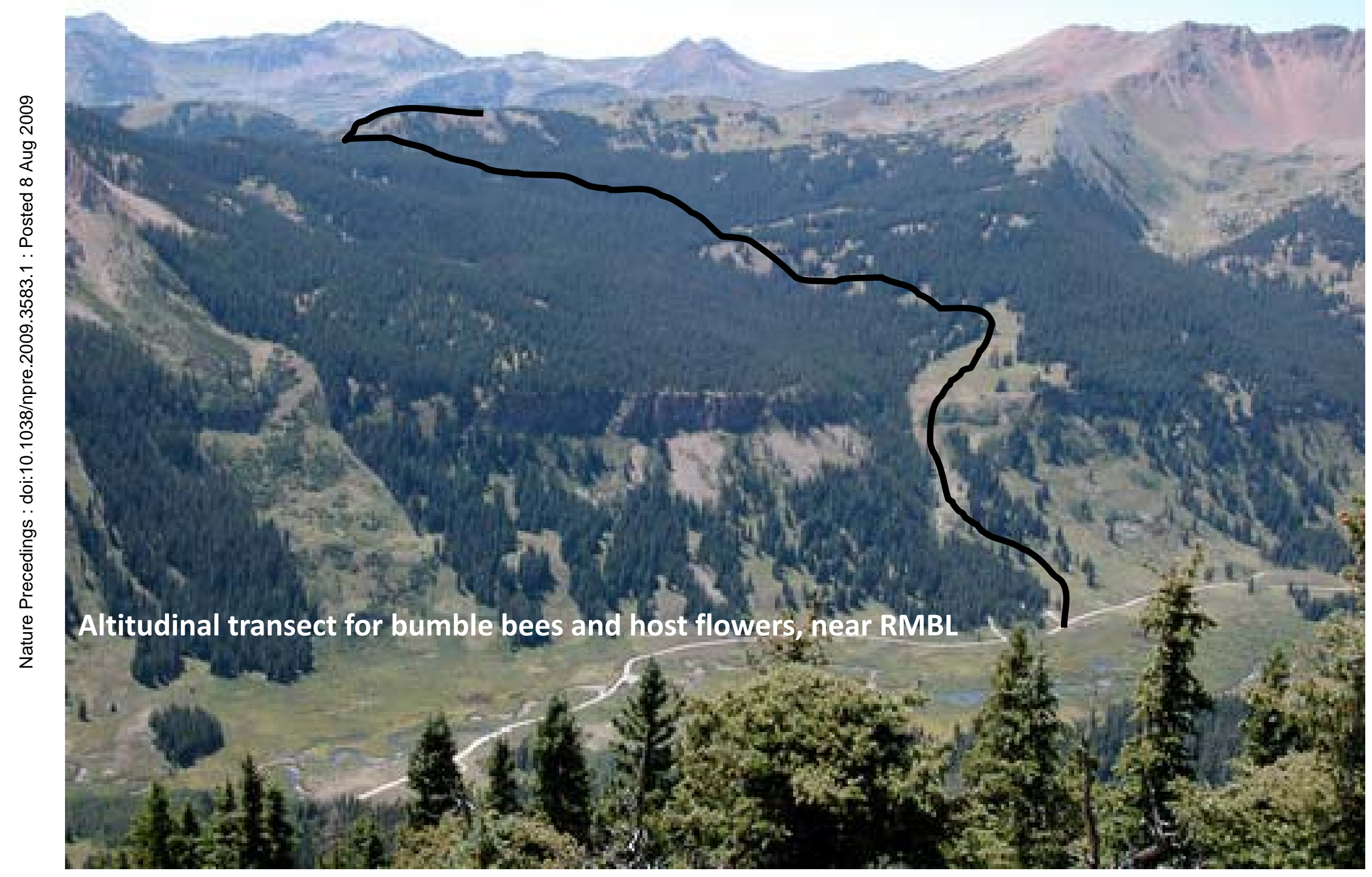




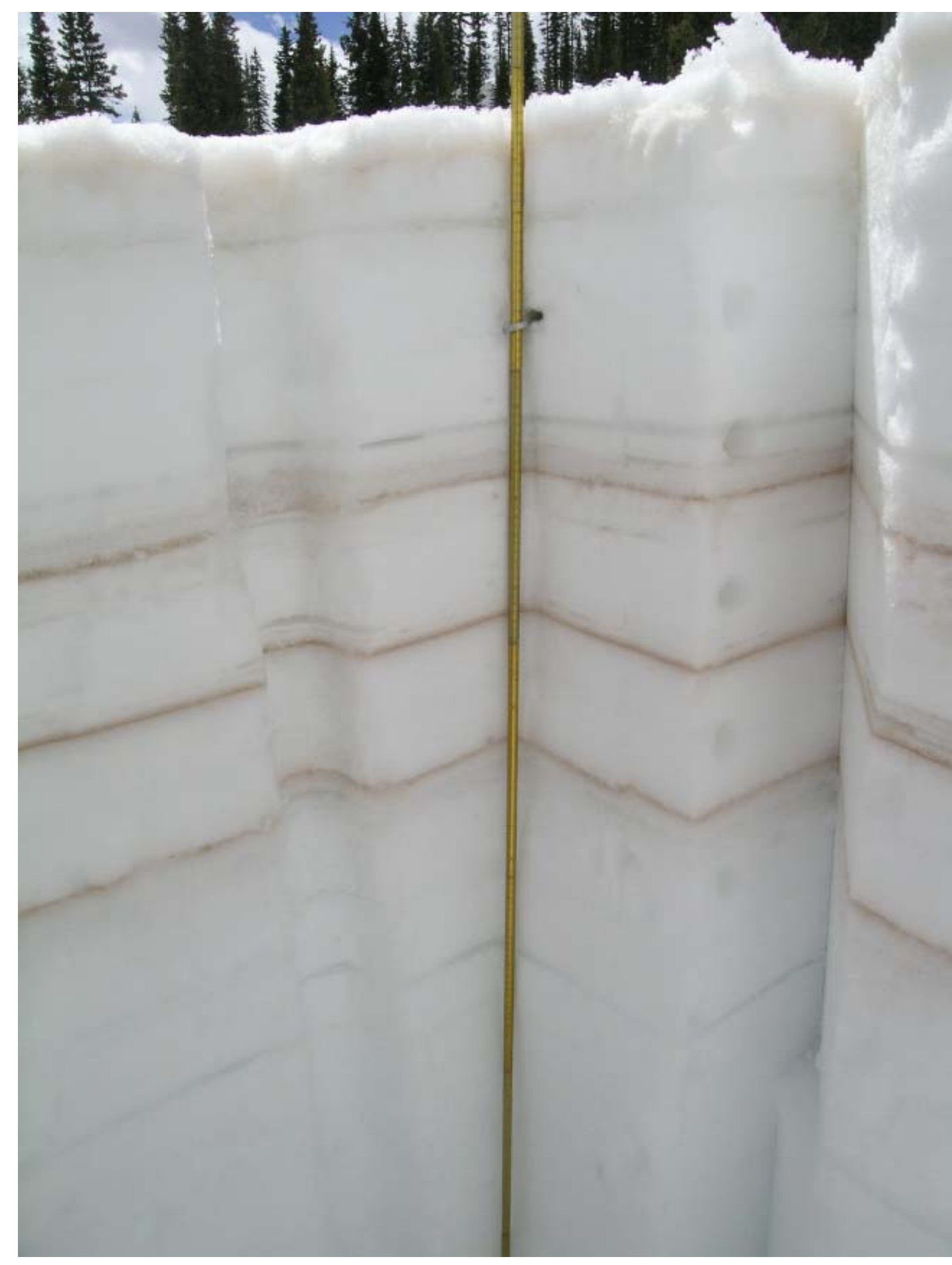

Photo of dust layers in the snowpack, spring 2009. Photo from the San Juan mountains, Colorado, by Chris Landry.

Photo Courtesy of Center for Snow and Avalanche Studies, Silverton Colorado 
$\longrightarrow$ Disturbed $\cdots \cdot$ Undisturbed

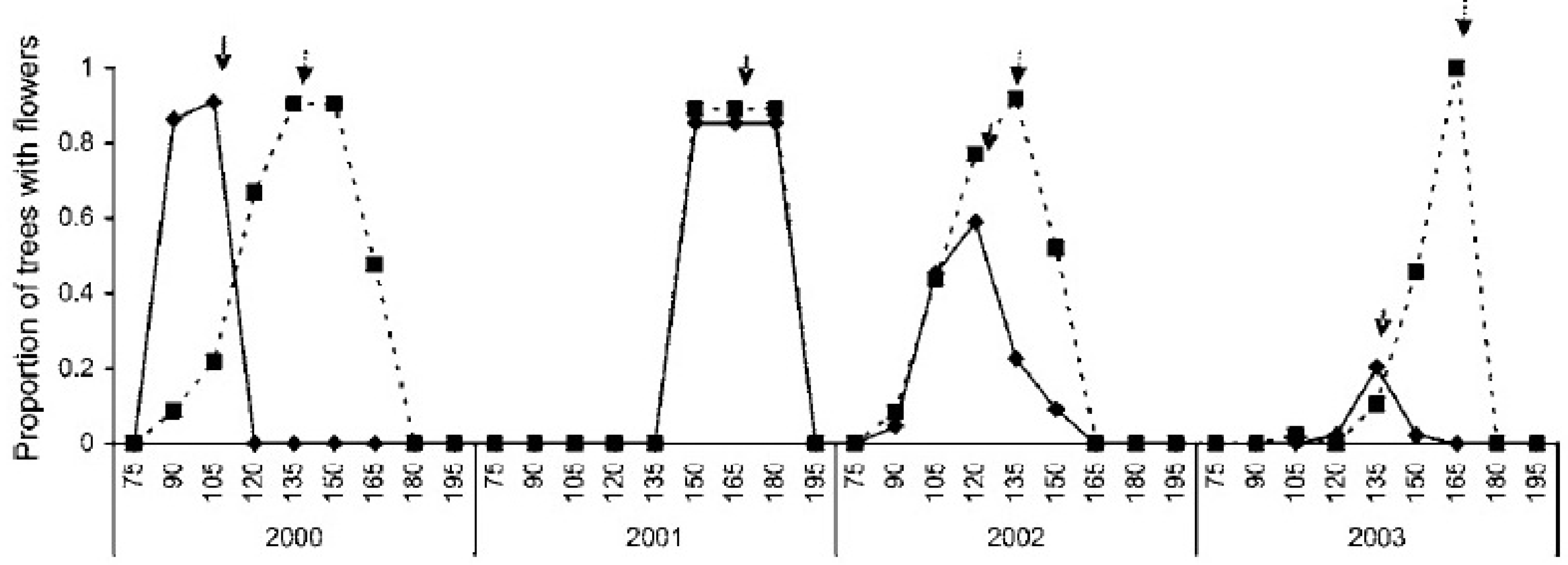

Herrerías-Diego, Y., M. Quesada, K. E. Stoner, and J. A. Lobo. 2006. Effects of florest fragmentation on phenological patterns and reproductive success of the tropical dry forest tree Ceiba aesculifolia. Conservation Biology 20:1111-1120. 


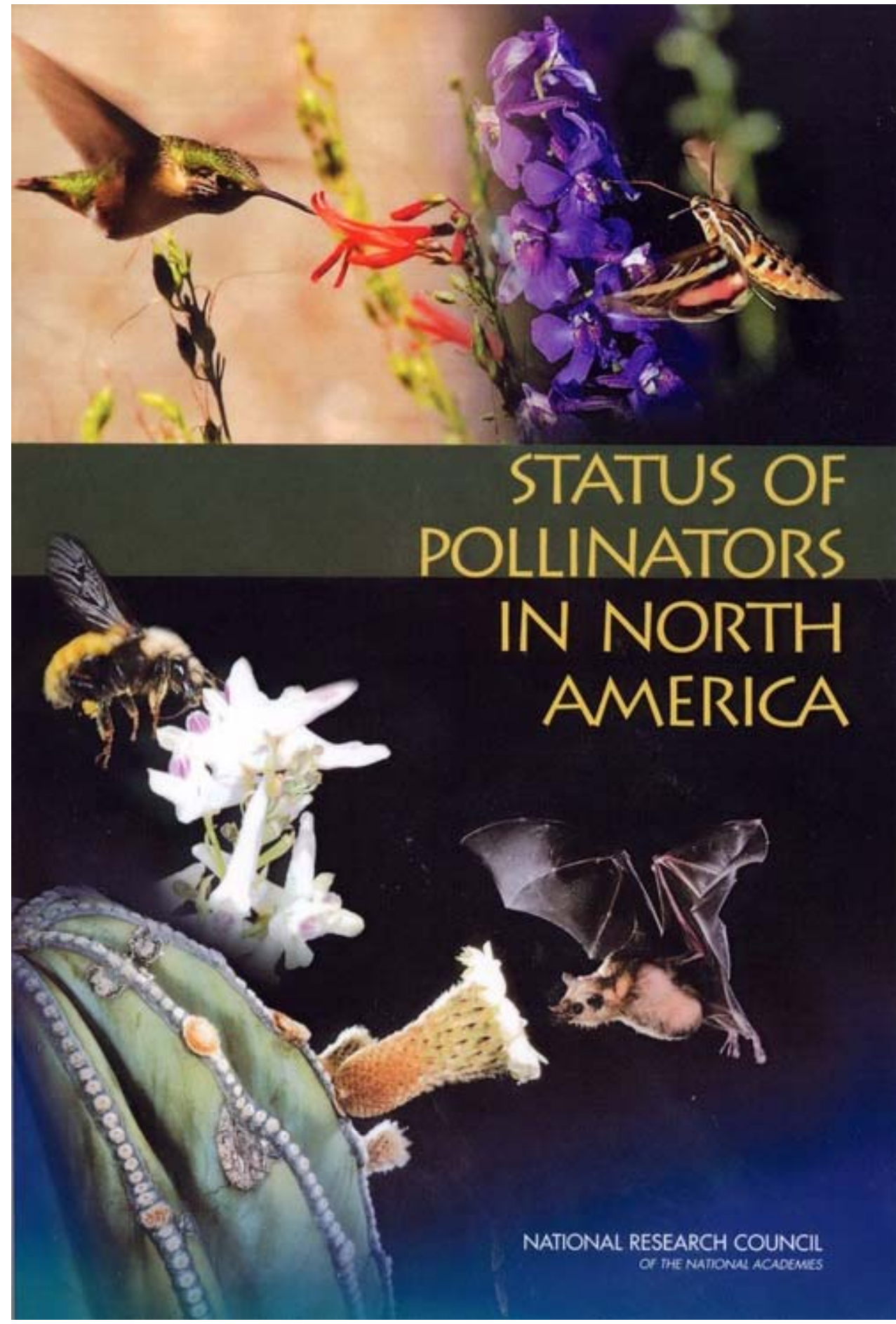

We need data on:

Pollinator distributions

Pollinator abundance

Pollinator phenology

Floral resource phenology

Floral resource abundance

Range changes

Phenology of interactions 
- In an environment that has been altered 1 suddenly by human activities, an organ $\mathrm{sm}$. makes a maladaptive behavioral or life history choice based on formerly reliable environmental cues, despite the availability of higher quality options.

- Schlaepfer, Runge \& Sherman 2002. 